\title{
Calibration and evaluation of the Canadian Forest Fire Weather Index (FWI) System for improved wildland fire danger rating in the United Kingdom
}

\author{
Mark C. de Jong ${ }^{1}$, Martin J. Wooster ${ }^{1,2}$, Karl Kitchen ${ }^{3}$, Cathy Manley ${ }^{4}$, Rob Gazzard ${ }^{5}$, and Frank F. McCall ${ }^{4}$ \\ ${ }^{1}$ King's College London, Department of Geography, UK \\ ${ }^{2}$ National Centre for Earth Observation (NCEO), UK \\ ${ }^{3}$ Met Office, Exeter, UK \\ ${ }^{4}$ Forestry Commission England, 620 Bristol Business Park, Coldharbour Lane, Frenchay, Bristol, BS16 1EJ, UK \\ ${ }^{5}$ Forestry Commission England, Bucks Horn Oak, Farnham, Surrey, GU10 4LS, UK
}

Correspondence to: Mark C. de Jong (mark.dejong@kcl.ac.uk)

Received: 28 April 2015 - Published in Nat. Hazards Earth Syst. Sci. Discuss.: 23 November 2015

Accepted: 8 April 2016 - Published: 30 May 2016

\begin{abstract}
Wildfires in the United Kingdom (UK) pose a threat to people, infrastructure and the natural environment. During periods of particularly fire-prone weather, wildfires can occur simultaneously across large areas, placing considerable stress upon the resources of fire and rescue services. Fire danger rating systems (FDRSs) attempt to anticipate periods of heightened fire risk, primarily for earlywarning and preparedness purposes. The UK FDRS, termed the Met Office Fire Severity Index (MOFSI), is based on the Fire Weather Index (FWI) component of the Canadian Forest FWI System. The MOFSI currently provides daily operational mapping of landscape fire danger across England and Wales using a simple thresholding of the final FWI component of the Canadian FWI System. However, it is known that the system has scope for improvement. Here we explore a climatology of the six FWI System components across the UK (i.e. extending to Scotland and Northern Ireland), calculated from daily $2 \mathrm{~km} \times 2 \mathrm{~km}$ gridded numerical weather prediction data and supplemented by long-term meteorological station observations. We used this climatology to develop a percentile-based calibration of the FWI System, optimised for UK conditions. We find this approach to be well justified, as the values of the "raw" uncalibrated FWI components corresponding to a very "extreme" (99th percentile) fire danger situation vary by more than an order of magnitude across the country. Therefore, a simple thresholding of the uncalibrated component values (as is currently applied in the MOFSI) may
\end{abstract}

incur large errors of omission and commission with respect to the identification of periods of significantly elevated fire danger. We evaluate our approach to enhancing UK fire danger rating using records of wildfire occurrence and find that the Fine Fuel Moisture Code (FFMC), Initial Spread Index (ISI) and FWI components of the FWI System generally have the greatest predictive skill for landscape fire activity across Great Britain, with performance varying seasonally and by land cover type. At the height of the most recent severe wildfire period in the UK ( 2 May 2011), $50 \%$ of all wildfires occurred in areas where the FWI component exceeded the 99th percentile. When all wildfire events during the 2010-2012 period are considered, the 75th, 90th and 99th percentiles of at least one FWI component were exceeded during 85, 61 and $18 \%$ of all wildfires respectively. Overall, we demonstrate the significant advantages of using a percentile-based calibration approach for classifying UK fire danger, and believe that our findings provide useful insights for future development of the current operational MOFSI UK FDRS.

\section{Introduction}

In this study we investigate how the use of the Canadian Forest Fire Weather Index (FWI) System (Van Wagner, 1987) for forecasting fire danger in the United Kingdom (UK) can be enhanced, using a percentile-based approach, and explore 
how the underlying components of the FWI System relate to historic fire activity in Great Britain (GB; the UK without Northern Ireland). Wildfires in the UK may not be as frequent or intense as those found in other regions of the world, e.g. North America or Australia, but uncontrolled landscape-scale fires do occur throughout much of the country, particularly in spring (Davies and Legg, 2008; Albertson et al., 2009). Anthropogenic and, to a lesser extent, naturally occurring fires have played a critical role in shaping UK ecosystems - notably in upland heath areas, but also in peatlands and grasslands (Davies et al., 2008).

While individual wildfires rarely present a serious threat to human life, they can cause considerable damage to livelihoods, infrastructure and the natural environment (Davies et al., 2008). Of particular concern is the threat that fire poses to peat soils found in upland areas, as they represent a significant store of the UK's terrestrial carbon (Milne and Brown, 1997). UK fires are almost exclusively anthropogenic, and generally result from accidental ignitions, arson or escaped burns conducted for land management purposes, e.g. for the maintenance and improvement of moorland grouse habitat (Davies et al., 2006; Albertson et al., 2009). The impact of these fires can be greatly exacerbated when periods of low fuel moisture coincide with wind speeds conducive to fire spread. During these periods, a large number of sustained ignitions may result in many landscape-scale fires burning near simultaneously across the UK, as happened most recently for example in 2003, 2006 and 2011. Such episodes place extreme stress upon the resources of fire and rescue services (FRS), in terms of both personnel and firefighting response assets (Davies and Legg, 2008). Accordingly, use of a fire danger rating system (FDRS) to forecast when and where these wildfire episodes are most likely is of growing interest to FRS and government agencies, as a sufficiently reliable operational system could enhance short-term wildfire response planning and resource allocation (Eastaugh et al., 2012).

The Met Office (the UK's national weather service) currently operates an FDRS for England and Wales - the Met Office Fire Severity Index (MOFSI; Met Office, 2015) based upon the FWI System. To date, however, relatively little calibration of the underlying FWI System has been carried out. We believe that there remains considerable potential for its adaptation in the UK, as it has been successfully adapted in a number of other fire-affected environments around the world (e.g. de Groot et al., 2007; Fogarty et al., 1998; Taylor and Alexander, 2006).

\section{Background}

\subsection{Fire danger rating systems}

The term "fire danger" generally "refers to an assessment of both fixed and variable factors of the fire environment (i.e. fuels, weather and topography) that determine the ease of ignition, rate of spread, difficulty of control, and impact of wildland fires" (Merrill and Alexander, 1987, in Taylor and Alexander, 2006, p. 122). An FDRS is generally designed to systematically evaluate and integrate these factors into qualitative and/or numerical indices of fire potential, primarily in order to guide fire management activities (Stocks et al., 1989; Lee et al., 2002). The most comprehensive FDRSs, such as the Canadian Forest Fire Danger Rating System (CCFDRS; Stocks et al., 1989), incorporate data that relate to all aspects of the fire environment, though many less sophisticated FDRSs are based entirely upon meteorological parameters, as data are easy to acquire and typically allow for a good estimation of the moisture content of dead fuels - generally the most flammable component of the fuel complex (Chuvieco et al., 2009). The MOFSI employed across England and Wales is one such meteorologically based FDRS, since it relies exclusively upon the FWI System, the meteorological module of the CCFDRS.

\subsection{The Canadian Forest Fire Weather Index System}

The FWI System (Van Wagner, 1987) is one of the most commonly used FDRSs globally (Taylor and Alexander, 2006; Lawson and Armitage, 2008), though it was originally developed for use in Canadian jack/lodgepole pine forest environments. The FWI System consists of six components, calculated from meteorological inputs: air temperature, wind speed, relative humidity and $24 \mathrm{~h}$ cumulative rainfall, each measured at noon local time (Van Wagner, 1987). The first three are "moisture codes" - the Fine Fuel Moisture Code (FFMC), the Duff Moisture Code (DMC) and the Drought Code (DC) - each relating to the moisture content of the three major ground fuels commonly found in a mature pine forest environment: the fine surface litter, loosely compacted organic material ("duff") and deeper organic layers/large surface fuels respectively (Van Wagner, 1987). These moisture codes are then used within the FWI System to determine three further "fire behaviour index" components, each providing information related to the potential behaviour of a fire should an ignition occur. The Initial Spread Index (ISI) represents the potential rate of fire spread, the Buildup Index (BUI) indicates the total amount of available combustible fuel, and the final "FWI" component combines the ISI and BUI to provide a measure of the potential frontal intensity of a fire. While originally developed for use in Canadian pine forests, the relative simplicity of the FWI approach has resulted in its extensive use in other environments, both within Canada and elsewhere, both for establishing new relationships between the FWI System components and the fuel moisture/fire behaviour observed in local fuels (e.g. Fogarty et al., 1998; de Groot et al., 2005, 2007; Palheiro et al., 2006; Taylor and Alexander, 2006) and for distinguishing periods of high fire activity (e.g. Bedia et al., 2014; Karali et al., 2014; Venäläinen et al., 2014). Furthermore, the FWI 
System has been found to outperform or at least match the performance of other FDRSs in terms of highlighting high fire activity periods in non-native environments (e.g. Dowdy et al., 2010; Viegas et al., 1999).

\subsection{Current fire danger rating in the UK}

Instigated in 2002, the UK MOFSI (Met Office, 2015) provides 5-day forecasts of the final FWI component of the FWI System for England and Wales. FWI forecasts are calculated using operational numerical weather prediction (NWP) data and classified into one of five fire danger categories (representing "low" to "exceptional" fire danger). The FWI System was adopted as the foundation for the MOFSI as it was found to highlight periods of high fire danger under a range of different weather conditions, it could identify periods of both short-term increased fire danger and periods when fire danger increased gradually over time, and it appeared to respond well to changing fire danger levels in different UK vegetation types (Kitchen et al., 2006; Met Office, 2005).

The MOFSI was originally designed as a decision support tool for land management organisations (e.g. Natural England, Natural Resources Wales) that, under the UK Government's Countryside and Rights of Way (CRoW) Act (2000), are responsible for restricting access to public land in England and Wales when fire danger reaches "exceptional" levels. UK-wide fire danger forecasts are also integrated into the Natural Hazards Partnership hazard assessment reports, issued daily to the UK government and nationwide emergency services to support planning and decision-making processes (http://www.metoffice. gov.uk/nhp/daily-hazard-assessment). While the MOFSI has proven suitable for its primary purpose of triggering the closure of public land under the CRoW (2000) Act, there exists significant scope for developing its use as a wider decision support tool for land managers, government agencies and emergency services (Legg et al., 2007; Davies and Legg, 2008). We suggest that the current system has several key limitations:

- The MOFSI "exceptional" category currently used to trigger land closures under the CRoW (2000) Act was defined relatively subjectively, based upon FWI conditions observed in the years 1976, 1995 and 2003 when UK wildfires were particularly widespread (Met Office, 2005). The lower categories were then defined based upon a geometric progression from this threshold. These thresholds do not correspond to any specific shifts in potential fire behaviour, suppression difficulty or ecological damage.

- The FWI threshold values used to define the fire danger categories of the MOFSI are held constant across the UK, which fails to take into account the significant climatic variations seen across the country, both in terms of latitude and elevation. As a result, in climatologically wetter, colder areas of the UK, a forecast FWI value that would be considered historically extreme for a particular location may actually only be categorised as "low" or "moderate" using the current MOFSI fire danger categories, even if the location has a history of wildfire occurrence.

- MOFSI only makes use of the final FWI component of the FWI System, despite the other components being considered fire danger indices in their own right (Camia and Amatulli, 2009). From a fire management perspective, depending upon the environment of interest, some of these components (and therefore ultimately the FWI, as it is constructed from these components) may be of limited relevance to fire danger rating. The DMC, DC and BUI are useful for tracking fuel moisture content (FMC) and total fuel availability in densely forested environments where large dead fuels and deep organic soils are present (Van Wagner, 1987). However, forest fires are relatively uncommon in the UK, and large dead fuels and deep organic soils are rare in other fireprone environments such as shrub and grassland, potentially reducing the importance of these components - though during periods of drought, these components may indicate when extremely ecologically damaging fires can occur in peat soils (Krivtsov et al., 2008). Furthermore, despite evidence that the DC can describe live FMC in shrub fuels (Viegas et al., 2001), live FMC has been shown to have minimal impact on fire behaviour in these environments (Anderson et al., 2015). Accordingly, as suggested by Van Wagner (1988), fire danger in many non-forested environments may be best reflected by FFMC or ISI alone.

\subsection{Improving fire danger rating in the UK}

To overcome some of the limitations of the MOFSI and enhance fire danger rating in the UK, we have developed and evaluated a new percentile-based FDRS. This approach is still based upon the FWI System but now makes use of individual NWP forecasts of each of the FWI System components, which are interpreted in the context of their historical range at a local level $(2 \mathrm{~km} \times 2 \mathrm{~km}$ grid cells $)$ as percentiles.

This percentile-based approach does not attempt to take explicit account of the complex relationships between weather and live fuel moisture/fire behaviour in specific fuel types, and it therefore is intended for broadly highlighting areas of extreme fire danger purely from a meteorological perspective rather than giving e.g. an indication of anticipated fire behaviour, potential levels of suppression difficulty or ecological damage. Ultimately, the "optimum" UK FDRS would likely be based upon new empirical relationships established between fuel moisture/fire behaviour in specific UK fuels and either (1) existing fire danger indices (e.g. FWI components) or (2) appropriate meteorological parame- 
ters. Indeed, such relationships are well understood for boreal forests (Alexander and de Groot, 1988; Taylor and Alexander, 2006) and have been derived for tropical grasslands (de Groot et al., 2005, 2007) and investigated in Mediterranean fuels (Viegas et al., 2001; Palheiro et al., 2006). While a number of studies have investigated these relationships in the UK (Davies et al., 2006, 2009; Davies and Legg, 2008, 2011; Legg and Davies, 2009; Legg et al., 2007), these relationships have proven challenging to establish in common UK fuel types such as heather and gorse (and analogous overseas fuels; e.g. Anderson and Anderson, 2009; Anderson et al., 2015). Accordingly, considerable further research - involving large-scale experimental burning campaigns - is needed in this field if a suitably robust, empirically based UK FDRS is to be developed.

A percentile-based method is, however, routinely used in the USA (Andrews et al., 2003) and has been tested by Dowdy et al. $(2009,2010)$ in Australia and Camia and Amatulli (2010) at a European level for assessing fire danger. We believe that this approach improves upon the existing UK system in several ways:

- by reducing the subjectivity of threshold selection for fire danger categories and by making these thresholds easier to understand

- by better accounting for the regional climate variations seen across the country, and allowing forecasts to be interpreted in a locally and historically relevant context

- by providing forecasts of each of the FWI components, the relative suitability of each of the components as fire danger indices in different UK environments can begin to be assessed (as we explore in this work). Eventually, each (or some) of these components may be used to inform specific fire management decisions, as they are in Canada (Wotton, 2009).

\section{Data sets}

The new UK FDRS developed herein was based upon, and tested with, two principal data sets. (1) A spatially and temporally detailed long-term UK record of the FWI components - a so-called "FWI climatology" (Sect. 3.1) - was used to define the extremes (and thus percentiles) of each component for each $2 \mathrm{~km} \times 2 \mathrm{~km}$ grid cell and season across the country. This data set formed the foundation of the percentilebased FDRS. (2) A record of fire incidence across Great Britain extracted from the UK FRS Incident Recording System (IRS) database (Sect. 3.2) and enhanced by land cover data (Sect. 3.3) was then used to examine percentiles of the FWI components during past wildfire periods.

\subsection{FWI climatology data}

To ensure that the percentile values of the FWI System components were based upon sound statistics, a data set capturing the long-term intra-seasonal variability of each FWI component was required, particularly because UK weather conditions that appear to lead to exceptional wildfire danger, and thus "extreme" values of the FWI components, seem to be relatively infrequent. The revised UK FDRS developed herein was based upon daily $2 \mathrm{~km} \times 2 \mathrm{~km}$ resolution Met Office NWP forecasts, and so this long-term "FWI climatology" should ideally also have been derived from a historical archive of these same data. Unfortunately, iterative changes and enhancements to the Met Office NWP system meant that a consistent archive at $2 \mathrm{~km} \times 2 \mathrm{~km}$ spatial resolution across the entire UK was only available since 2010, limiting us to a record spanning only 4 years (2010-2013; hereafter termed the "NWP-derived" FWI data set). To develop a longer-term climatology, we also made use of FWI System components derived from a more temporally extensive (several decades) data set of station-based meteorological observations taken from across the UK (hereafter termed the "met station-derived" FWI data set). Since the ultimate aim of the UK FDRS is to derive useful fire danger forecasts from NWP forecasts, the met station-derived FWI data set was primarily used to assess whether the limited 4-year period covered by the NWP-derived FWI data set was of sufficient statistical robustness to be used to derive meaningful percentiles for each of the FWI System components. Further detail on the NWP- and met station-derived FWI data sets is provided in the following subsections.

\subsubsection{NWP-derived FWI data}

For the period 1 January 2010-16 December 2013, we calculated a daily NWP-derived FWI data set from the Met Office NWP model $24 \mathrm{~h}$ (midday to midday) accumulated rainfall and matching daily noon air temperature, wind speed and relative humidity data for each $2 \mathrm{~km} \times 2 \mathrm{~km}$ grid-cell (Met Office, 2013a). Due to problems with the NWP archive, no data were available for the periods 1 January 2013-20 June 2013 and 5 August 2013-30 September 2013, inclusive, resulting in a $\sim 3.3$-year data set, consisting of 1217 individual daily forecasts of each FWI System component.

\subsubsection{Met station-derived FWI data}

The met station-derived FWI data set was calculated from noon air temperature, relative humidity and wind speed values and $24 \mathrm{~h}$ cumulative rainfall totals extracted from hourly observation records for 38 UK meteorological stations (Met Office, 2013b). The stations used were operational during the 2010-2013 NWP data period, and all have much longer-term data availability; the longest running station data set covers a 44.0-year period from 1 January 1970 until 31 December 
2013, with the median and shortest running station data sets extending back from December 2013 for 21.9 and 13.3 years respectively. Sites are well distributed around the UK, ensuring capture of regional climate variations.

\subsection{Historic fire data: the Great Britain Fire and Rescue Service Incident Recording System}

The FRS Incident Recording System (IRS) provides detailed information on all fires reported in Great Britain (England, Scotland and Wales) since 2009 (DCLG, 2012, 2013). We made use of 3 years (January 2010-December 2012) of outdoor "vegetation fire" records from this database to investigate how percentiles of the FWI System components relate to fire activity. No similar data set was available for Northern Ireland, so Great Britain rather than the entire UK was the focus of the evaluation component of our work. The IRS database provides a variety of information for each vegetation fire incident, and of particular relevance for this study were

- fire location (coded as a six-figure British National Grid Reference)

- time between reporting and extinction of fires

- estimated burned area

- number of firefighting appliances in attendance.

While the IRS database offers very useful information on fire occurrence, it is important to note that it was designed as an operational tool, and trade-offs may have been made in terms of data quality for the sake of recording speed. For example, burned area estimates and land cover classification (see Sect. 3.3) are believed to be very approximate. As such, caution is required when using these data for scientific studies.

Most vegetation fires in Great Britain are very small in size, with the median area burned per fire during the study period estimated to be $2.5 \mathrm{~m}^{2}$. As meteorological fire danger is likely to have limited influence on individual small fires, we filtered out these incidents and retained only those fires that could be classified as "wildfires", as the term can be well defined and understood in both a policy and operational context. The criteria set out in the Scottish FRS Wildfire Operational Guidance (Scottish Government, 2013) are typically used to distinguish wildfires from small vegetation fires in the UK. Consequently, in this work, IRS incidents were only considered wildfires if they met one or more of the following criteria from the Scottish guidance:

- burned area $>1$ ha

$->6 \mathrm{~h}$ elapsed between reporting and extinction

- > 3 firefighting appliances were in attendance.
Using these criteria, 2921 IRS incidents recorded between January 2010 and December 2012 were identified as wildfires and retained for further analysis. These wildfires accounted for $1.5 \%$ of all vegetation fires and $97.5 \%$ of the total burned area recorded during this period.

\subsection{Land cover data}

Analysis of fire records collected before the instigation of the IRS found that fire and rescue services frequently recorded the parked location of FRS appliances as the incident location and that these locations could be potentially up to $3 \mathrm{~km}$ apart (MacKinnon, 2008; McMorrow et al., 2011). The IRS has improved location accuracy (McMorrow et al., 2011); however, there is believed to be uncertainty associated with the correct identification of land cover type in the database. Therefore, instead of using the land cover classifications recorded in the IRS data set, we determined the land cover type for each fire incident using a combination of three spatial land cover data sets. The UK Land Cover Map 2007 (LCM2007; Morton et al., 2011) was used to classify most (84\%) incidents. $9 \%$ of incidents occurred in areas mapped in the more spatially detailed National Forest Inventory (NFI; Forestry Commission England, 2012) and so were classified using this data set instead. Where data were available for both data sets, for some incidents there was considerable disagreement between the NFI and LCM2007 classifications; e.g. an area could be classified as woodland by the NFI but as arable by the LCM2007. In these cases (7\% of all incidents), the highly detailed Ordnance Survey MasterMap ${ }^{\circledR}$ Topography Layer data set (Ordnance Survey, 2014), digitised from aerial photography, was used to determine the final classification. The resulting land cover classifications were then aggregated into one of seven broad categories: broadleaved woodland, coniferous woodland, arable, grassland, heath/bog/marsh, urban and other.

\section{Methodology}

\subsection{Development of a percentile-based FDRS}

For each $2 \mathrm{~km} \times 2 \mathrm{~km}$ grid square in the NWP-derived FWI data set, we calculated the seasonal values of the 10th-90th percentile of each FWI component (in intervals of 10), creating nine percentile "reference" data sets. Five additional reference data sets were also calculated for the 1st, 5th, 95th, 97th and 99th percentiles to capture the extremes of each FWI component's range in greater detail. These reference data sets form the foundation of the percentile-based FDRS; any NWP-derived forecast of a FWI component for a particular grid cell and season could now be converted to a percentile value by linearly interpolating between the reference data set values. For the purposes of this study, we split the calendar year into four 3-month-long seasons that broadly correspond to the meteorological seasons experienced in the 
UK: spring (March, April, May), summer (June, July, August), autumn (September, October, November) and winter (December, January, February).

For context, the 99th percentile of an FWI component corresponds to 3-4 days over the entire 3.3-year NWP data set, for each season. Examination of the NWP data set suggests that for the relatively fast responding, wind-affected FWI components (FFMC, ISI, FWI), this equates to $\sim 1$ day per season per year exceeding the 99th percentile. For the slower responding components (DMC, DC, BUI), the 34 days above the 99th percentile are often temporally sequential, representing "one in several year extreme" conditions.

\subsection{Evaluating the suitability of the NWP-derived FWI data set as the basis for a percentile-based FDRS}

To assess whether the newly constructed NWP-derived FWI data set (and thus the percentile reference data sets derived from it) was a suitable basis for a new FDRS, we needed to address whether these 3.3 years of data were representative of the longer-term met station-derived FWI climatology. This was done by a statistical comparison of the NWP-derived FWI data set and the much longer-term met station-derived FWI data set.

In fact, agreement between the NWP- and met stationderived FWI data at matched locations was found to be relatively poor on a day-to-day basis (not shown here). Similar observations have been made elsewhere (Legg et al., 2007; Dowdy et al., 2010). This is likely a result of differences in the spatial scales of the two data sets (individual meteorological station locations vs. $2 \mathrm{~km} \times 2 \mathrm{~km}$ grid cells), which can be particularly important for rainfall, due to the occurrence of sub-grid-scale convective events and the impact of complex terrain (e.g. Hoadley et al., 2004; Finkele et al., 2006; Field et al., 2015). However, a comparison of the 99th percentiles of the met station-derived and NWP-derived FWI data sets suggests that their upper extremes are similar. To demonstrate this, 99th percentiles were calculated seasonally for each meteorological station in the met station-derived FWI data set for the January 2010-December 2013 period (termed the "post-2010" met station-derived FWI data set 99th percentiles), matching the temporal extent of the NWP-derived FWI data set. For each FWI component, these percentile values were then compared to those from the 99th percentile reference data set (extracted from the $2 \mathrm{~km} \times 2 \mathrm{~km}$ grid cells containing the meteorological stations) using ordinary leastsquares (OLS) linear regression.

Furthermore, to investigate whether the variation in FWI components between 2010 and 2013 was reasonably representative of a longer-term FWI climatology, the 99th percentiles were calculated seasonally for each meteorological station in the met station-derived FWI data set for the period prior to January 2010 (termed the "pre-2010" met stationderived FWI data set 99th percentiles). OLS linear regression models were then calculated for the pre-2010 and post-2010 met station-derived 99th percentile data for each FWI component to compare the two periods.

\subsection{Exploring the percentile-based FDRS using historic fire records}

After developing our percentile-based FDRS using the NWPderived data set, we examined the behaviour and predictive skill of the FWI System components in relation to the historic IRS wildfire records. These data were explored in detail for a number of particularly "extreme" wildfire incidents (Sect. 4.3.1), and then an intercomparison of the components was performed using the ranked percentile curve approach of Eastaugh et al. (2012) to identify the components that best highlight fire danger in the UK (Sect. 4.3.2). Additionally, the distributions of raw FFMC data during wildfires was also investigated, as previous studies (e.g. de Groot et al., 2005, 2007; Davies and Legg, 2008; Wotton et al., 2009) have identified FFMC thresholds below which wildfire activity is extremely rare.

\subsubsection{Analysis of FWI System components during historic wildfire events}

Since each of the FWI components can be considered a fire danger index in its own right (Camia and Amatulli, 2009), we used the NWP-derived data set to investigate peak values of each of the FWI components during the IRS wildfire events. While most wildfires were $<1$ day in duration, $22 \%$ of spring, $29 \%$ of summer and $51 \%$ of autumn events were multi-day events. For each event, daily and event-maximum FWI component values were extracted from the corresponding NWP-derived data set grid cell. These raw FWI component values were then converted to seasonal percentile values via a linear interpolation of the percentile reference data sets.

Additionally, to illustrate the potential impact of our new spatial varying percentile-based FDRS and to highlight the differences between it and the MOFSI, we used a contingency table approach to assess the forecasting skill of both approaches on 2 May 2011. This date was selected as it coincides with one of the most extreme UK wildfire periods experienced during 2010-2013, when 66 wildfires were identified as simultaneously burning across Great Britain. The midnight $12 \mathrm{~h}$ NWP-derived forecast of the FWI component was classified using both the MOFSI and percentile-based FDRS, and the resulting fire danger maps were geographically intersected with the IRS wildfires. Using these data, contingency tables (Doswell et al., 1990) were constructed for both forecasting approaches. A wildfire event was considered correctly forecast by the percentile-based FDRS if the forecast FWI value for the grid cell containing the fire exceeded the 90th percentile and by the MOFSI if the forecast value was classified as "high", "very high" or "extreme". Forecast skill of the two approaches was then compared using the extremal 
dependence index (EDI; Ferro and Stephenson, 2011):

$\mathrm{EDI}=\frac{\log F-\log H}{\log F+\log H}$,

where $H$ is the hit rate and $F$ is the false alarm rate. The hit rate is defined as

$H=\frac{x}{x+y}$,

where $x$ is the number of correctly forecast fire events and $y$ is the number of missed fire events. The false alarm rate is defined as

$F=\frac{z}{w+z}$,

where $z$ is the number of fire events forecast but not observed and $w$ is the number of correctly forecast non-events. The EDI has been developed specifically for the verification of rare event forecasts, as the ability of most traditional performance metrics used to demonstrate model skill decreases with decreasing event frequency. EDI values range between $[-1,1]$, with scores $>0$ considered more skilful than a random forecast. A full description of the EDI properties is provided in Ferro and Stephenson (2011).

\subsubsection{Intercomparison of the FWI System components during historic wildfire events using ranked percentile curves}

In certain environments, some FWI components are believed to be better predictors of fire danger than others (Van Wagner, 1988). Consequently it is useful to compare the performance of each component relative to one another. As noted by Verbesselt et al. (2006a), evaluating the performance of fire danger rating systems is challenging since the concept of fire "danger" is rather ill-defined. Nevertheless, whilst fires can occur under many different "fire weather" situations, it should be the case that ignitions are more likely to be sustained and wildfires more difficult to control during conditions of "elevated" fire danger. Accordingly, a number of studies have attempted to evaluate the skill of various fire danger indices via comparisons to historical fire records (e.g. Viegas et al., 1999; Andrews et al., 2003; Verbesselt et al., 2006b; Dowdy et al., 2010; Arpaci et al., 2013; Eastaugh and Hasenauer, 2014). A percentile-based evaluation method was appealing for such a comparison, since these data were readily available to us and they are uninfluenced by the differences in frequency distributions and scales of the raw components. Comparing differences in percentiles on fire/nonfire days between indices, as used previously by Andrews et al. (2003), can form a simple yet effective evaluation method, but the choice of percentiles for evaluation can influence which index is considered to have greatest skill (Eastaugh et al., 2012). Therefore, we elected to use the "ranked percentile curve" approach devised in the Eastaugh et al. (2012) review of fire danger index comparators. This method has subsequently been applied by Arpaci et al. (2013) and Eastaugh and Hasenauer (2014).

A brief description of the ranked percentile curve approach of Eastaugh et al. (2012) is provided here. For fire danger indices with a daily time resolution, all index values are first converted to percentiles, and the percentiles on days on which fires occurred ("fire days") are extracted and plotted by ascending rank to create a ranked percentile curve. A nonparametric regression model is then fit to this curve using the Theil-Sen method (Theil, 1950a, b, c; Sen, 1968), selected because it is more resistant to outliers than other regression techniques (due to the fact that the slope and intercept are determined using a median-based approach; Helsel and Hirsch, 2002; Granato, 2006). This resistance to outliers is well suited to the evaluation of meteorological fire danger indices, since the causes of wildfires extend well beyond the meteorological factors that are the only factors accounted for by the FWI components (e.g. variations in human activities - caused for example by weekend vs. weekday activities might tend to lead to many more ignitions on particular days of the year). For illustrative purposes, Fig. 1 shows TheilSen models for three hypothetical fire danger indices: a "perfect" index (i.e. the highest index percentile possible occurs on each fire day) where slope $=0$ and intercept $=100$; a fire danger index with no predictive skill (i.e. the distribution of percentiles on fire days is the same as on non-fire days) where slope $=$ the maximum observed percentile value divided by the total number of fire days and intercept $=0$; and an index with some predictive skill, where slope and intercept values fall between the "perfect" and "no skill" indices. Accordingly, intercept and slope values from the Theil-Sen model fits to the fire danger index data can be used to assess index skill and allow comparison between different indices.

The relationships between fire behaviour, fuel moisture and meteorology change across different environments and by time of year (e.g. Davies and Legg, 2008, 2011; Padilla and Vega-García, 2011); thus, the performance of the FWI components for forecasting UK fire danger is likely to vary seasonally and between land cover types. A study by Legg et al. (2007) investigated the predictive power of the raw FWI components in Scotland and areas of England by examining data on fire days and non-fire days in grass, heath, bush/gorse and forest woodland environments. They concluded that the FFMC, ISI and FWI have broadly equivalent discriminatory power for fire occurrence, while the DC is of little value. Our study builds upon this approach as we make use of data for the whole of Great Britain, and we believe that a climatologically based percentile approach may be more powerful than using raw FWI component data.

Accordingly, in our study we performed two seasonal ranked percentile curve analyses of the FWI components during wildfire incidents - the first at a national level for spring, summer and autumn, and the second disaggregated by land cover type for spring and summer. Too few fire 
Table 1. Number of wildfire events and burned area data reported in Great Britain between January 2010 and December 2012 from the filtered UK Fire and Rescue Service Incident Recording System (IRS) data set developed herein, disaggregated by season and land cover type. See Sect. 3.3 for details on land cover classification.

\begin{tabular}{|c|c|c|c|c|c|c|}
\hline \multicolumn{2}{|c|}{ Land cover type } & \multirow{2}{*}{$\begin{array}{c}\text { Spring } \\
151\end{array}$} & \multirow{2}{*}{$\begin{array}{c}\text { Summer } \\
204\end{array}$} & \multirow{2}{*}{$\begin{array}{c}\text { Autumn } \\
172\end{array}$} & \multirow{2}{*}{$\begin{array}{c}\text { Winter } \\
38\end{array}$} & \multirow{2}{*}{$\begin{array}{c}\text { Total } \\
565\end{array}$} \\
\hline \multirow{9}{*}{ 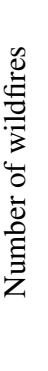 } & Arable & & & & & \\
\hline & Broadleaved & 183 & 70 & 17 & 6 & 276 \\
\hline & Coniferous & 137 & 63 & 15 & 5 & 220 \\
\hline & Grassland & 701 & 176 & 61 & 23 & 961 \\
\hline & Heath/bog/marsh & 269 & 35 & 12 & 2 & 318 \\
\hline & Other & 17 & 8 & 7 & 2 & 34 \\
\hline & Urban & 278 & 159 & 84 & 26 & 547 \\
\hline & Total & 1736 & 715 & 368 & 102 & 2921 \\
\hline & Total (discounting other/urban) & 1441 & 548 & 277 & 74 & 2340 \\
\hline \multirow{9}{*}{ 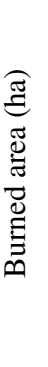 } & Arable & 881 & 685 & 223 & 13 & 1802 \\
\hline & Broadleaved & 7648 & 219 & 7 & 8 & 7883 \\
\hline & Coniferous & 1425 & 46 & 2 & 5 & 1478 \\
\hline & Grassland & 12262 & 215 & 42 & 37 & 12555 \\
\hline & Heath/bog/marsh & 24546 & 809 & 117 & 1 & 25474 \\
\hline & Other & 358 & 12 & 1 & 2 & 373 \\
\hline & Urban & 1828 & 171 & 40 & 4 & 2043 \\
\hline & Total & 48949 & 2158 & 432 & 71 & 51609 \\
\hline & Total (discounting other/urban) & 46763 & 1975 & 390 & 64 & 49192 \\
\hline
\end{tabular}

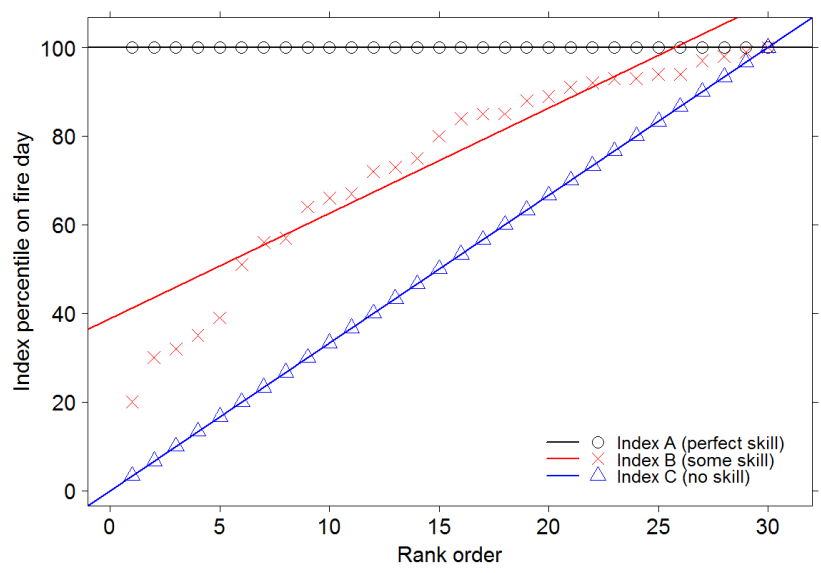

Figure 1. Demonstration of the use of data from three hypothetical fire danger indices (indices A, B and C) fitted with Theil-Sen models to compare the indices' predictive skill on fire days. Index A demonstrates perfect skill (i.e. the highest index percentile value possible occurs on each fire day) and so slope $=0$ and intercept $=$ 100 for the Theil-Sen model fit to these data. The model fit to index B (which shows some predictive skill) has a smaller intercept and larger slope than the model fit to index A but a larger intercept and smaller slope than the model fit to index $\mathrm{C}$ (an index with no predictive skill). Accordingly, by comparing the slope and/or intercept values of Theil-Sen models fit to percentile data from two or more fire danger indices, the relative predictive skill of the indices can be determined. See Eastaugh et al. (2012) for more details on this approach to skill assessment. events occurred in autumn to perform an adequate analysis at land cover level, and the winter NWP-derived FWI data were considered to be unsatisfactory for further analysis (see Sect. 5.2 for more details). Using the maximum FWI component percentile values associated with each IRS wildfire event, ranked percentile curves and Theil-Sen models were constructed for each FWI component, both at a national level and split by broad UK land cover type. For both the national and land cover level analyses only wildfires identified as occurring in "arable", "broadleaved", "coniferous", "grassland" or "heath/bog/marsh" environments were considered, since these accounted for the majority of recorded British wildfire events $(80 \%)$ and area burnt (95\%; see Table 1). Additionally, fires in classes such as "urban" will actually be occurring in an unknown land use sub-class (e.g. grassland, parkland).

\section{Results and discussion}

\subsection{Characteristics of historic UK fires: analysis of the IRS database}

The spatial and seasonal distributions of wildfire activity in Great Britain (January 2010-December 2012) and the spatial distribution of the aggregated UK land cover types are shown in Fig. 2. A breakdown of wildfire activity (fire counts and burned area) by both land cover type and season is also provided in Table 1. During this period, a total of 2921 wildfires burned an area of 51609 ha. From Fig. 2b it is appar- 


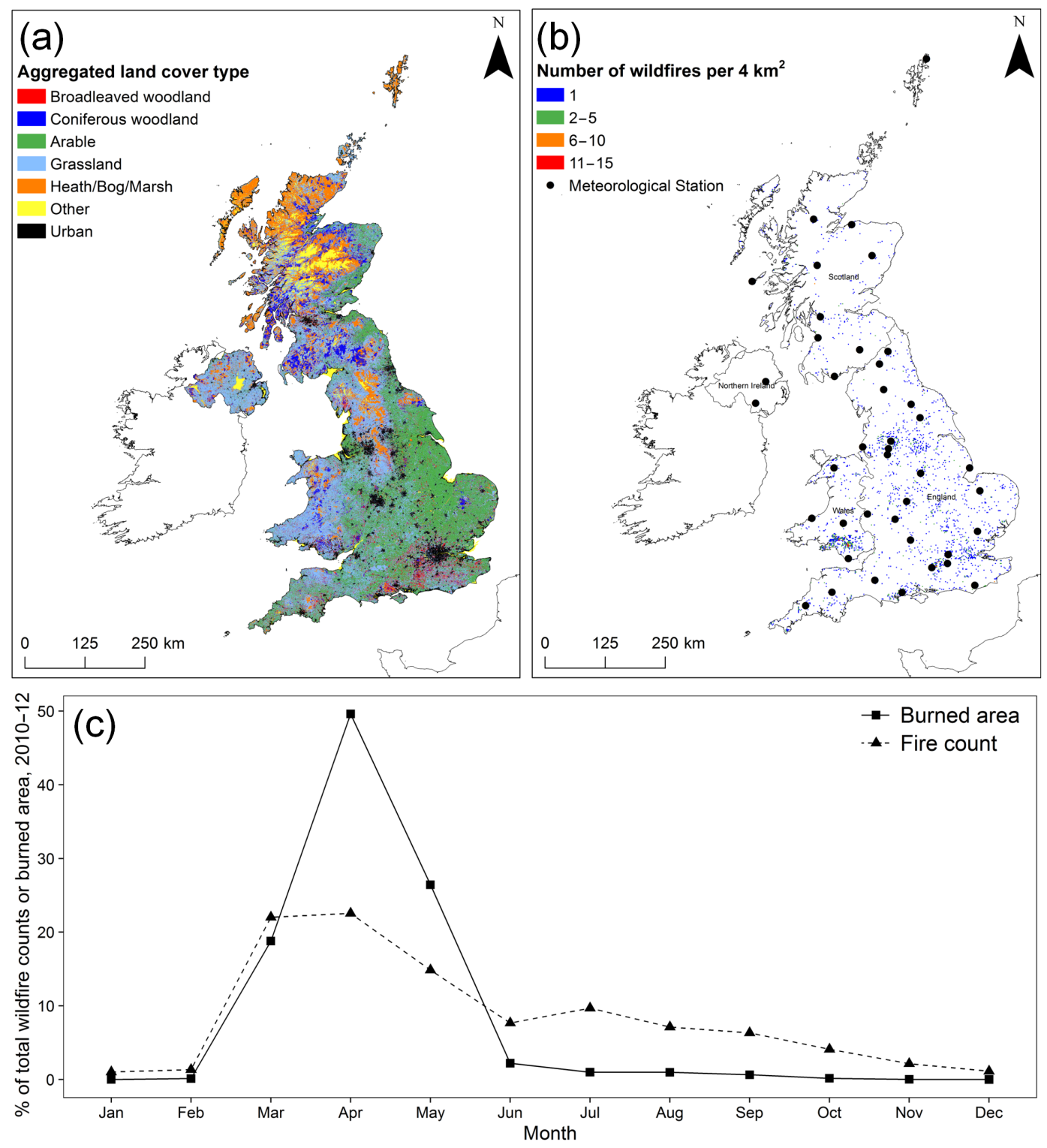

Figure 2. Land cover, meteorological station and fire occurrence data in the study area. Panel (a) shows the distribution of the aggregated UK land cover classes as derived from the Land Cover Map 2007 (LCM 2007; Morton et al., 2011). Spatial and temporal distributions of wildfire activity in Great Britain (England, Wales and Scotland) are shown in panels (b) and (c), as recorded by the Fire and Rescue Service (FRS) Incident Recording System (IRS) between January 2010 and December 2012. The locations of the 38 meteorological station sites used herein to create the long-term "met station-derived" FWI data set are also shown (black circles) in (b). In addition to the availability of vegetation cover able to support the spread of fire, the anthropogenic influences on fire occurrence can be clearly discerned from (b), with loci of increased fire density in south Wales, south east England and the southern Pennines region of northern England. During this three year period, $59 \%$ of wildfires, accounting for $95 \%$ of total burned area, occurred during spring (March, April and May). Another $24 \%$ of wildfires occurred during summer (June, July and August), accounting for $4 \%$ of total burned area. Panel (a) is based upon LCM2007 ${ }^{\circledR}$ NERC (CEH) 2011. Based upon LCM2007 ${ }^{\circ}$ NERC (CEH) 2011. Contains Ordnance Survey data ${ }^{\odot}$ Crown Copyright 2007 , ${ }^{\circledR}$ third party licensors.

ent that wildfires occur in all areas of the UK, although the number of wildfires per $2 \mathrm{~km} \times 2 \mathrm{~km}$ grid cell was highest in south Wales, south east England and the southern Pennines region of northern England. Spatial patterns of burned area are very similar (not shown). From Fig. 2c wildfire ac- tivity can be seen to be highly seasonal, with the majority of events (59\% of events, $95 \%$ of burned area) occurring in spring (March, April and May). Summer (June, July and August) fire occurrence was still relatively high (24\%), although these fires make a less significant contribution to to- 
tal burned area $(4 \%)$. Few wildfires $(13 \%)$ occurred in autumn (September, October and November) and winter (3\%; December, January and February), and these fires contribute very little to the total area burned $(0.8$ and $0.1 \%$ respectively).

Of all land cover types, "grassland" accounts for the largest proportion of wildfires in terms of wildfire occurrence (Table 1), both on an annual basis (33\%) and during spring $(40 \%)$. In terms of burned area "heath/bog/marsh" wildfires are particularly significant, accounting for 49 and $52 \%$ of total annual and spring burned area respectively. This is probably a consequence of the widespread managed burning that is typically carried out during spring (Albertson et al., 2009). The majority of summer wildfires occurred in "arable" $(29 \%)$ or "grassland" $(25 \%)$ land cover types, though once again the largest total area burned occurred in the "heath/bog/marsh" class $(38 \%)$. "Arable" wildfires dominated both total fire occurrence $(47 \%)$ and burned area $(52 \%)$ in autumn .

\subsection{Evaluation of the suitability of the NWP-derived FWI data set as the basis for an FDRS}

Figure 3 presents the seasonal relationships observed between the 99th percentile values of the FWI components derived from (a) meteorological station data and NWP data from grid cells geographically intersected by these stations, for the 2010-2013 period, and (b) meteorological station data for pre- and post-2010 periods for the same stations, with OLS linear regression fits and coefficients of determination $\left(r^{2}\right)$. The geographical locations of the meteorological stations used for this analysis are shown in Fig. 2b.

As observed in Fig. 3a, a strong association between post2010 met station-derived and NWP-derived FWI percentiles exists for all FWI System components during UK spring and summer ( $r^{2}$ min: 0.55, median: 0.82, max: 0.93). With the exception of ISI $\left(r^{2}=0.33\right)$, strong relationships are also found during autumn (median $r^{2}=0.70$ ). Relatively low bias is observed in the spring, summer and autumn seasons, with slope values for all FWI components lying between 0.73 and 1.30. As the extreme percentiles of the NWP-derived and the met station-derived FWI data are generally in good agreement, the NWP-derived FWI data were considered a suitable basis for a FDRS in spring, summer and autumn. Poorer association is observed between winter percentiles ( $r^{2}$ min: 0.19, median: 0.35, max: 0.78), and considerable positive biases are evident in the DC intercept value (166.26) and DMC, BUI and FWI slope values (2.67, 2.93 and 2.58 respectively). However, as the summer/spring period is generally of most concern for wildfires in the UK (see Fig. 2 and Table 1) this is not considered to be a significant issue.

Figure $3 \mathrm{~b}$ shows that while many of the relationships between the pre- vs. post-2010 met station-derived FWI data set 99th percentiles are relatively strong $\left(r^{2}>0.5\right)$; they are generally weaker than those between the NWP-derived and post-2010 met station-derived 99th percentiles (Fig. 3a). The poorest agreements and greatest biases are observed in the DMC and the BUI in winter and autumn and in the DC in winter and spring. Whilst the spring is a particularly important period for UK wildfires (Fig. 2c), the poor DC agreement $\left(r^{2}=0.4\right)$ is strongly influenced by data from a single meteorological station located in Marham, Norfolk. Outside of this station, the spring and summer 99th percentiles from the 2010-2013 period agree reasonably well with the 99th percentiles observed in the longer term for the other FWI components (median $r^{2}$ for all FWI components in spring and summer $=0.64$ ). Notably, 99th percentile values are generally higher in the pre-2010 data set, particularly for the slower responding components (DMC, DC, BUI), suggesting that the post-2010 period data set does not entirely capture all of the longer-term extremes of fire danger associated with infrequent drought periods.

Our findings above suggest that the NWP-derived FWI data set captures reasonably well the long-term variability of the FWI components seen in the UK during spring and summer (and for most FWI components, during autumn as well) and thus forms a suitable foundation for a percentilebased FDRS. Given the weak relationships observed both between met station-derived and NWP-derived data and preand post-2010 data in the winter months, we believe that this approach is not suitable for assessing winter fire danger in its current form, and so the remaining work carried out in this paper focus on the months of spring, summer and autumn. In any case, as Fig. 2c shows, winter wildfires are much rarer in the UK than fires at other times of year. It is also worth noting that an operational system developed based upon this approach would become more robust over time as additional years of data are added to the FWI climatology. This could improve some of the weaker relationships highlighted above and better represent the full range of fire danger conditions, including decadal/multi-decadal extreme episodes.

\subsection{Spatial variation in percentiles and its implications for a UK FDRS}

For all FWI components and seasons, a large degree of spatial variability exists in the percentile reference data sets. Figure 4 gives an example of this spatial variability, illustrating the variation observed in the 99th percentile of the FWI component across the UK, for spring, summer and autumn. In all seasons, the 99th percentile varies by over an order of magnitude across the country - clearly demonstrating the benefit of fire danger classes set using percentile-based FWI thresholds that are allowed to vary spatially, rather than thresholds that are fixed spatially for the entire UK, as is currently the case under the current MOFSI. In summer for example (Fig. 4b), the value of the FWI 99th percentile varies from 1.6 in western Scotland to 56.0 in south east England. By comparison, the MOFSI threshold for the "exceptional" fire danger class in summer is set to an FWI value of 52.4. In 

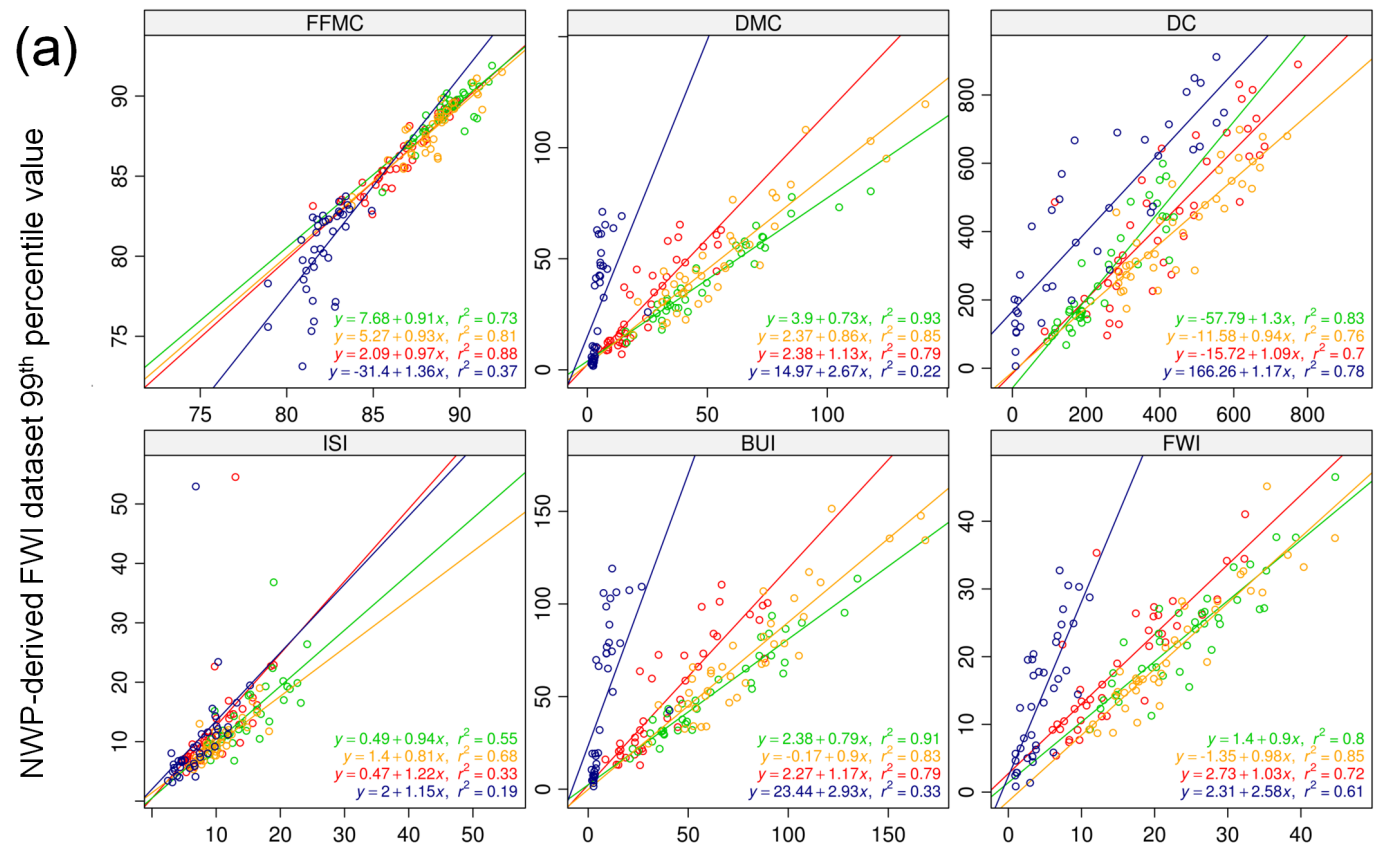

Post-2010 met station-derived FWI dataset $99^{\text {th }}$ percentile value
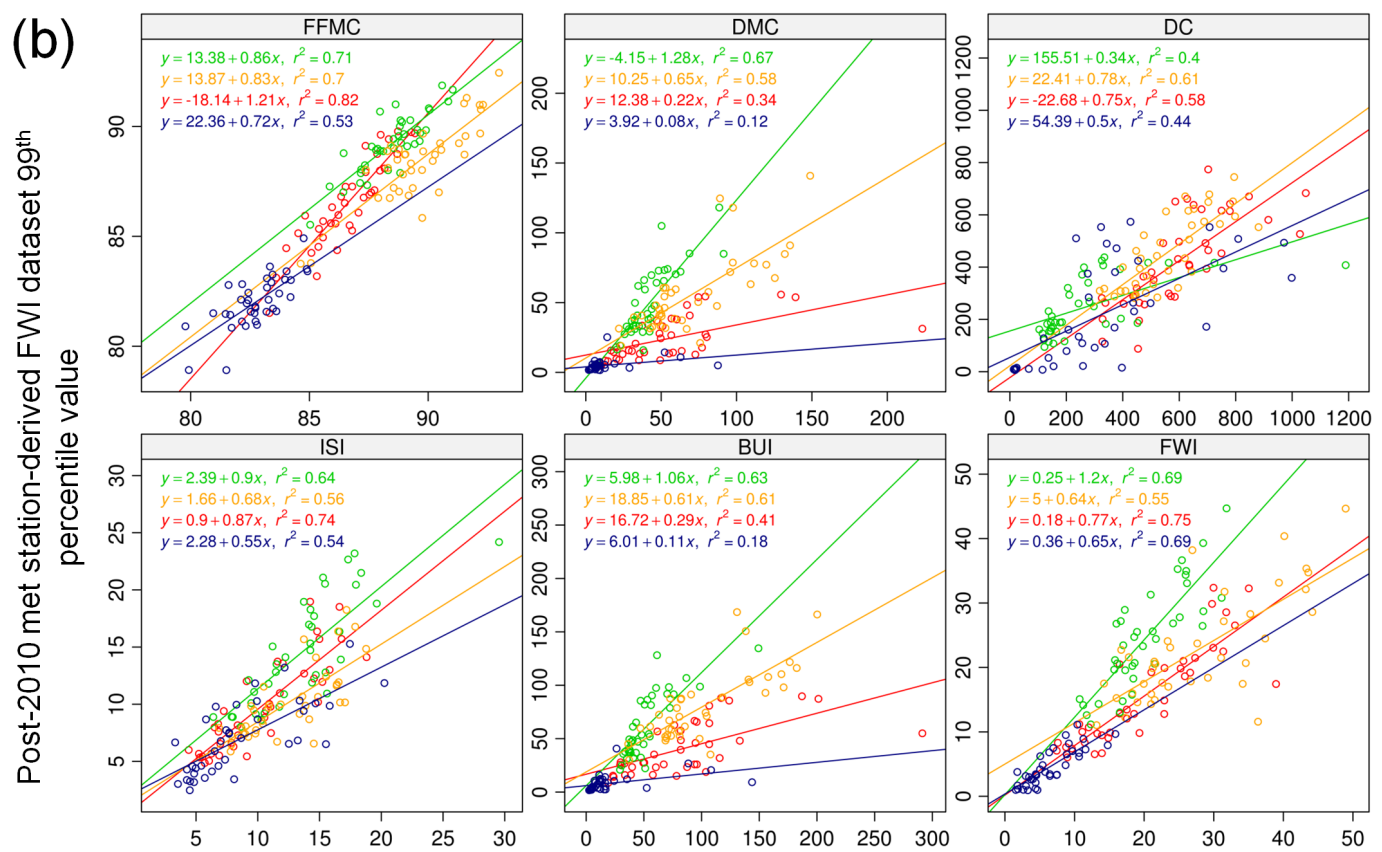

Pre-2010 met station-derived FWI dataset $99^{\text {th }}$ percentile value

$\circ$ Autumn $\quad \circ$ Spring $\circ$ Summer $\circ$ Winter

Figure 3. Comparison of the 99th percentile values of the six FWI System components by season, derived (a) from meteorological station data and NWP data from grid cells geographically intersected by these stations, for the 2010-2013 period, and (b) from meteorological station data for the pre- and post-2010 periods for the same stations, with OLS linear regression fits. Data in (a) indicate that extreme values of the FWI components calculated from the NWP-derived FWI data are similar to those calculated from meteorological station data during spring, summer and autumn. (b) shows that while there is some variation in the extreme FWI component values observed between 2010 and 2013 and the pre-2010 data (each met station used in this study has 13-44 years of data, including the years 2010-2013), the data from spring, summer and to a lesser extent autumn from 2010-2013 are broadly representative of longer-term extremes. Accordingly, we conclude that a robust FWI climatology can be constructed from the NWP-derived FWI data set for these seasons, despite its limited duration. 

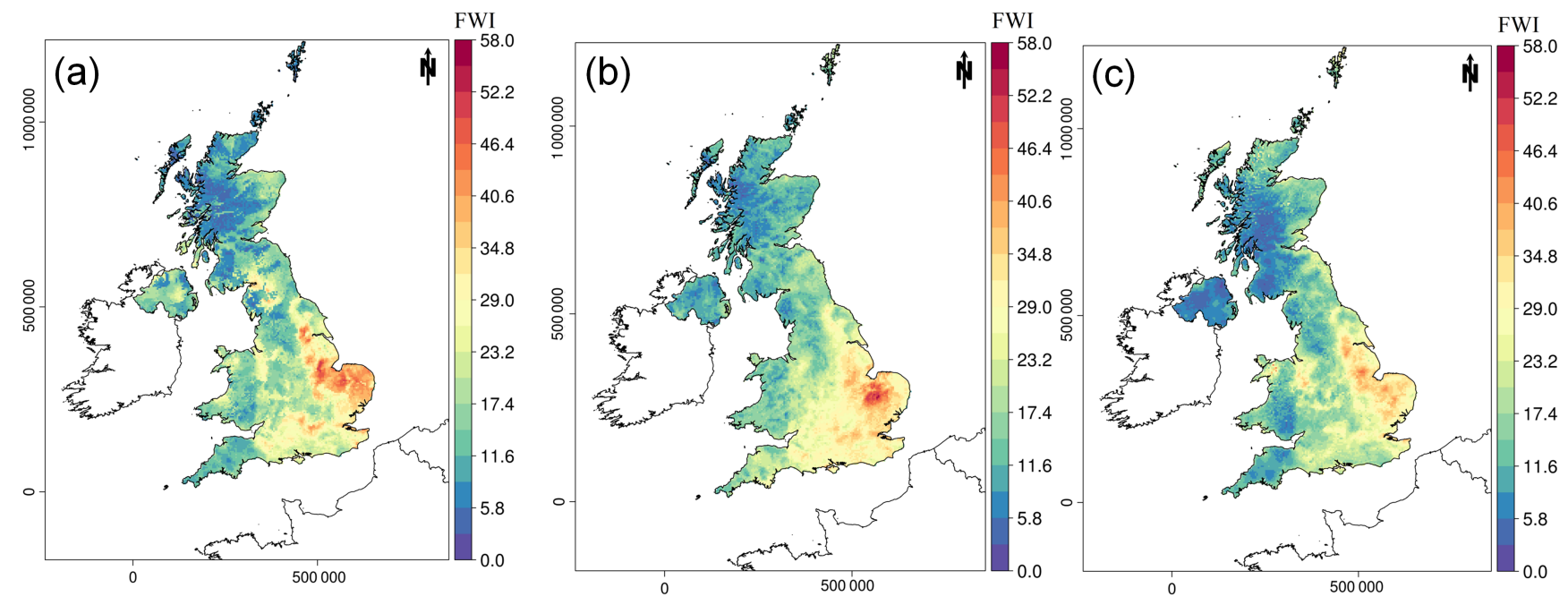

Figure 4. Spatial variation in the 99th percentile of the FWI component of the Canadian Fire Weather Index, as calculated from the 20102013 NWP-derived FWI data set for (a) spring, (b) summer and (c) autumn. The warmer, drier climate of south east England as compared to the wetter, cooler climate of the western and northern parts of the UK causes a distinct gradient in this percentile, which varies by an order of magnitude across the country.

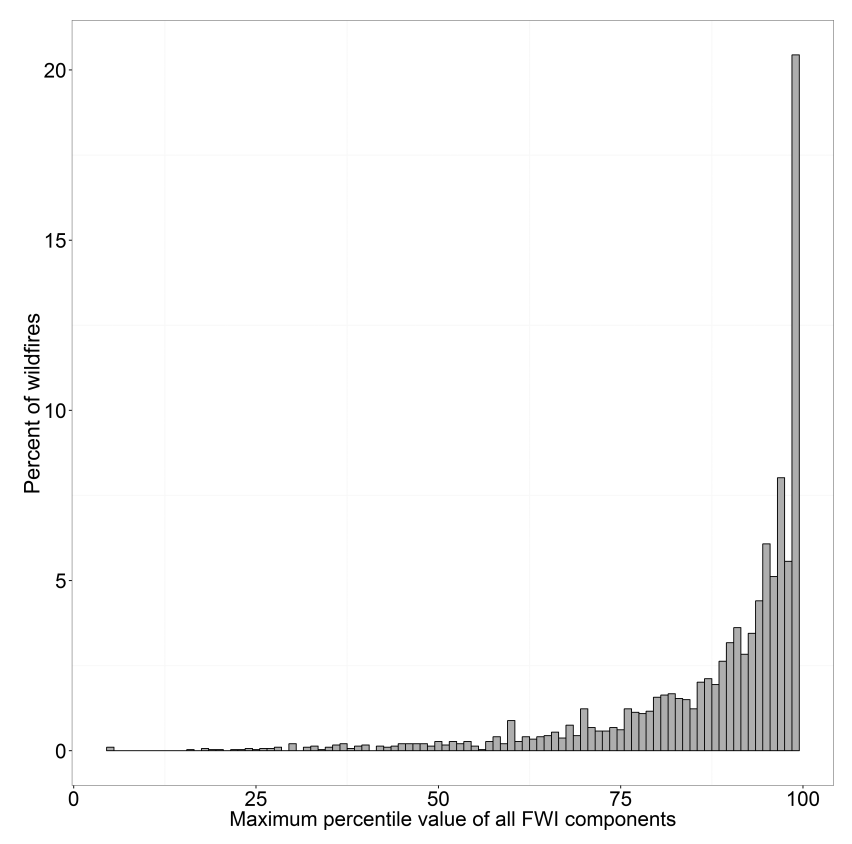

Figure 5. Frequency distribution of the maximum percentile value calculated for all of the FWI components during each event, for all IRS wildfires recorded in 2010-2012. For each IRS wildfire event, the maximum percentile value of each of the six FWI components was calculated, and the largest of these was then used to construct this frequency distribution.

many parts of the country that are fire-prone, such as western Scotland, even when fire danger is locally extreme, under the MOFSI conditions are highly unlikely to be classified as "exceptional". As can be seen from Fig. 4, much lower FWI val- ues represent extreme conditions in parts of northern/western England, Wales, Scotland and Northern Ireland than in central/south east England in all seasons, despite fire activity in the UK occurring across the entire country (Fig. 2b). Thus, adopting locally calculated percentiles as thresholds for fire danger categories avoids the geographical bias inherent in the existing MOFSI and would more realistically reflect extreme fire weather conditions for the entire UK.

\subsection{Analysis of FWI System components during historic wildfire events}

For each IRS wildfire event, the maximum percentile value of each of the six FWI components was calculated. A frequency distribution (Fig. 5) was then constructed using the highest of these values from each event. This heavily skewed distribution indicates that extreme percentile values of at least one component were forecast during the majority of wildfire events. The 75th, 90th and 99th percentiles of at least one FWI component were exceeded during 85,61 and $18 \%$ of all wildfires respectively. The temporal evolution of FWI component forecasts is shown in Fig. 6 for the period surrounding the widely reported spring 2011 Swinley forest fire, which burned 300 ha of woodland in Berkshire, south east England. This event is of particular note because of the large number (202) of firefighting appliances in attendance (Department for Communities and Local Government, 2013), the location was at the rural/urban interface of a densely populated area, and crown fire activity occurred, which in itself is a rare event in the UK (Kitchen, 2012). While the incident as reported by the IRS spans the period of 27 April-9 May, the fire only became highly significant in terms of fire suppres- 


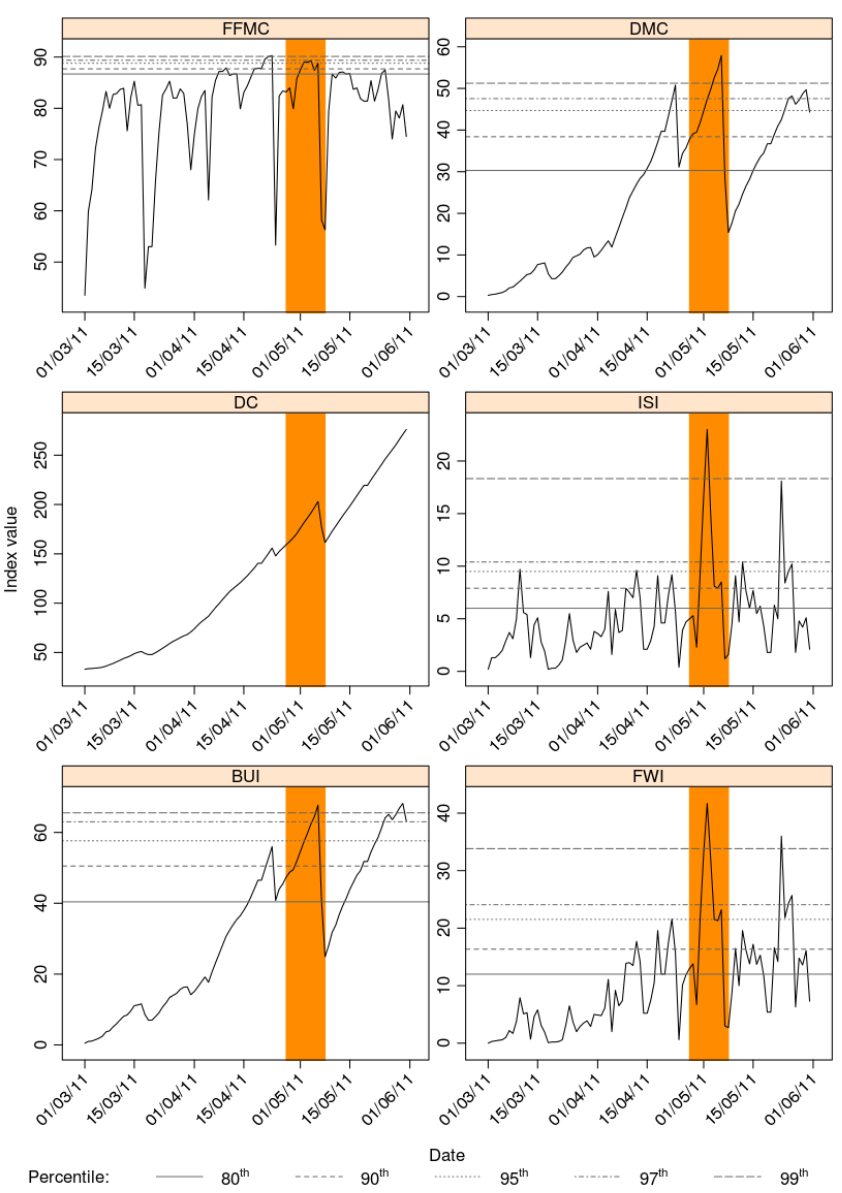

Figure 6. Temporal evolution of the FWI components at the location of the Swinley Forest wildfire that occurred in Berkshire, England, in April/May 2011. This fire was one of the most extreme fire events in the UK for many years, and it burned for 13 days according to the Incident Recording System database (timing indicated by the orange bars). Peak fire activity occurred on 2 May, and extreme behaviour persisted until 6 May (Kitchen, 2012). Horizontal dashed lines indicate the 80th, 90th, 95th, 97th and 99th percentiles of each FWI component for this particular UK grid cell during the spring season, calculated according to the criteria described in Sect. 4.1. The ISI and FWI components in particular have extreme maxima during this fire, with the high ISI values highlighting the importance of wind speed for this event.

sion efforts between 2 and 6 May (Kitchen, 2012). As Fig. 6 shows, percentiles of the slower-reacting FWI components (DMC, DC, BUI) steadily build up before this date and, with the exception of the DC, each component peaks in magnitude above the 95-99th percentile during the event. Similar behaviour of the FWI components is observed during other wildfire events (not shown). Given that FWI forecasts would be available from the Met Office NWP system 5 days prior to the actual date on which peak fire activity occurred, these data confirm that percentile-based FWI component forecasts contain significant information for short-term planning and decision-making by UK FRS and government agencies.

The midnight $12 \mathrm{~h}$ NWP-derived FWI component forecast for 2 May 2011 as classified using (a) the MOFSI and (b) the percentile-based approaches is mapped in Fig. 7, with active wildfires marked as hollow circles. As anticipated, large spatially dependent differences are seen between fire danger mapped using the MOFSI and percentile-based classification systems (Fig. 7). In this example, the highest fire danger is forecast in southern areas of the UK using the MOFSI approach (Fig. 7a), despite wildfire activity actually occurring nationwide. The percentile-based approach (Fig. 7b) better highlights the extreme nature of the fire weather conditions that existed across much of the country at this time, with $50 \%$ of fires occurring in areas where the FWI exceeded the 99th percentile. Contingency tables (Tables 2, 3) have been constructed for both approaches using the Great Britain NWP forecast data and wildfire records shown in Fig. 7. EDI values for the percentile-based and MOFSI approaches were 0.22 and 0.08 respectively, indicating that the percentile-based approach has substantially better forecasting skill. We consider an EDI value of 0.22 to be a good result for this specific forecasting application, as it is strongly constrained by the relationship between meteorological fire danger and actual wildfire occurrence. The percentile-based FDRS is intended to highlight areas of high meteorological fire danger, which, while indicative of where fires may occur, is not deterministic. While large areas of the country may indeed have been highly meteorologically conducive to wildfire on this date, appropriate fuel/topographical conditions and/or human caused ignitions also necessary for wildfires to occur would likely have been absent in many of these areas. Without consideration of these other factors, a high false alarm rate (many grid cells with conducive conditions, but no wildfire activity) as obtained here $(F=0.82)$ is to be expected.

\subsection{Comparing performance of the FWI System components across all IRS wildfire events}

\subsubsection{Evaluation of the FWI System components at national level}

Seasonal ranked percentile curves and Theil-Sen models for each FWI component at national level (all land cover types), constructed using the maximum value of each FWI component during each wildfire event, are presented in Fig. 8. From Fig. 8a and c, it can be seen that FFMC and ISI are the best-performing indices with respect to wildfire occurrence in spring and autumn respectively. The FFMC, ISI and FWI components exhibit broadly similar forecasting skill during these seasons, consistently outperforming the DMC, BUI and DC. The FWI shows the greatest skill in summer (Fig. 8b), with an intercept similar to that observed in spring. While FFMC and ISI skill is relatively worse in summer than in spring, DMC, DC and BUI all perform somewhat better. 

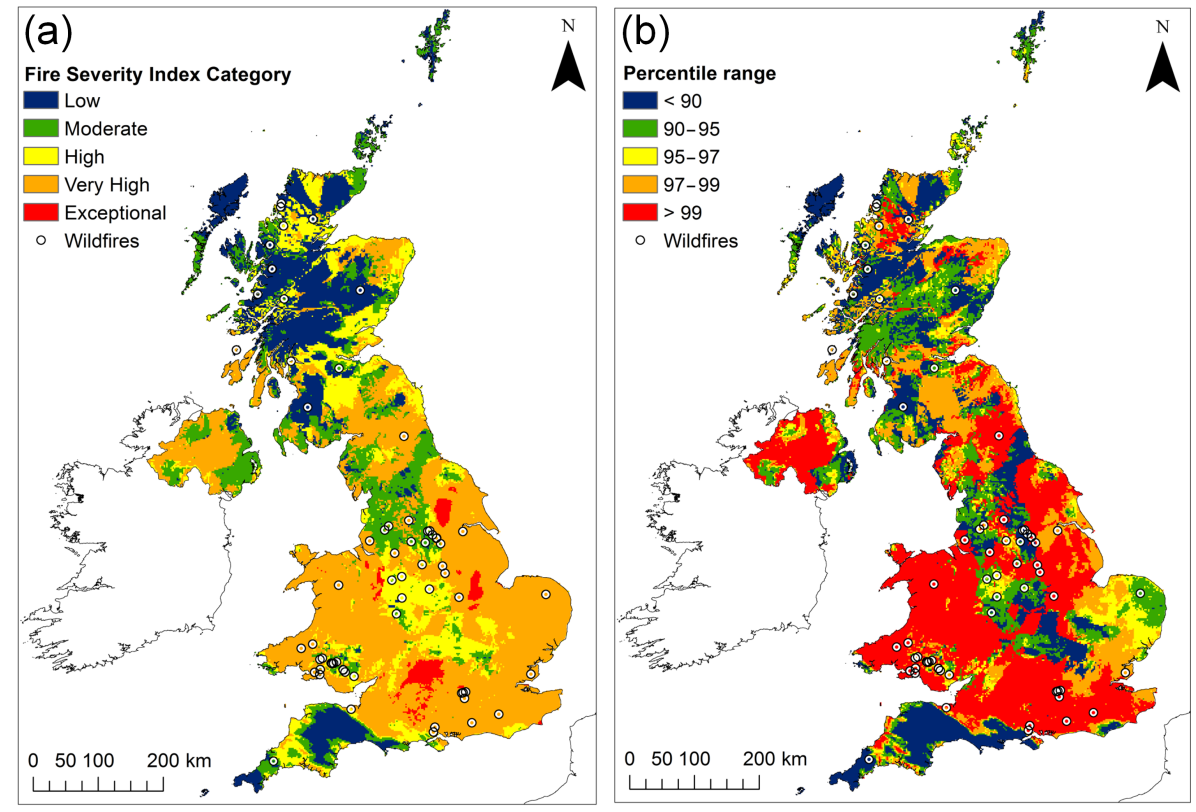

Figure 7. Fire danger in the UK, mapped for 2 May 2011, based upon the midnight $12 \mathrm{~h}$ NWP-derived FWI component forecast, classified using (a) the existing Met Office Fire Severity Index (MOFSI) (Kitchen et al. 2006; Met Office, 2005) and (b) the percentile-based FDRS described herein. This date coincides with the height of a period of extreme wildfire activity seen across Great Britain in spring 2011, related to weather conditions extremely conducive to vegetation fire spread, with 66 wildfires reported in the Fire and Rescue Service Incident Recording System (IRS) as burning in mainland Britain on 2 May 2011. These incidents are shown as hollow circles on both maps. No fire data for Northern Ireland are recorded in the IRS. In (a) the most extreme FWI conditions are confined to relatively small regions of England, whereas in (b) the most extreme conditions are much more widespread and are found across the entire UK, as is the fire activity.

Table 2. Contingency table for the midnight $12 \mathrm{~h}$ NWP-derived Fire Weather Index (FWI) component forecast for 2 May 2011, classified using the Met Office Fire Severity Index (MOFSI) described in Kitchen et al. (2006) and Met Office (2005). Each $2 \mathrm{~km} \times 2 \mathrm{~km}$ grid cell within Great Britain is represented as a unit value and assigned to one element of the $4 \times 4$ matrix below, based upon whether a fire is burning in that particular grid cell and whether fire danger conditions are conducive to fire. For the purpose of this analysis, grid cells where the FWI value was categorised as "high", "very high" or "exceptional" were considered to be conducive to fire. Wildfire observations are taken from the IRS database. Hit rate $(H)=0.71$, falsealarm rate $(F)=0.67$, extremal dependence index $(\mathrm{EDI})=0.08$.

\begin{tabular}{lccc}
\hline \multirow{2}{*}{ Forecast } & \multicolumn{2}{c}{ Observed } & \\
\cline { 2 - 3 } & Fire & No fire & Total \\
\hline Fire conducive & 47 & 41371 & 41418 \\
Not fire conducive & 19 & 20370 & 20389 \\
Total & 66 & 61741 & 61807 \\
\hline
\end{tabular}

Our results highlight the fact that during spring, the moisture content of slow-drying fuels (reflected in the DMC, DC and BUI) is generally high, preventing combustion even if an ignition were present. However, fires are frequent in spring due to the so called "spring dip" - where the moisture content of live vegetation is generally lower than in summer due
Table 3. Contingency table for the midnight $12 \mathrm{~h}$ NWP-derived fire weather index (FWI) component forecast for 2 May 2011, classified using the percentile-based FDRS. Each $2 \mathrm{~km} \times 2 \mathrm{~km}$ grid cell within Great Britain is represented as a unit value, and assigned to one element of the $4 \times 4$ matrix below, based upon whether a fire is burning in that particular grid cell, and whether fire danger conditions are conducive to fire. For the purpose of this analysis, grid cells where the FWI value $>90$ th percentile were considered to be conducive to fire. Wildfire observations are taken from the IRS database. Hit rate $(H)=0.88$, false-alarm rate $(F)=0.82$, extremal dependence index $(\mathrm{EDI})=0.22$.

\begin{tabular}{lccc}
\hline & \multicolumn{2}{c}{ Observed } & \\
\cline { 2 - 3 } Forecast & Fire & No fire & Total \\
\hline Fire conducive & 58 & 50481 & 50539 \\
Not fire conducive & 8 & 11260 & 11268 \\
Total & 66 & 61741 & 61807 \\
\hline
\end{tabular}

to limited leaf canopy development (Davies and Legg, 2008; Alexander and Cruz, 2012) - and thus fires are more likely to take hold if an ignition is sustained. As a result, spring wildfires are dependent on whether fine fuels are dry enough to allow self-sustaining ignitions, and spread is enhanced by elevated wind speed - factors reflected in the FFMC and ISI. In contrast, UK summer wildfires tend to occur during ei- 


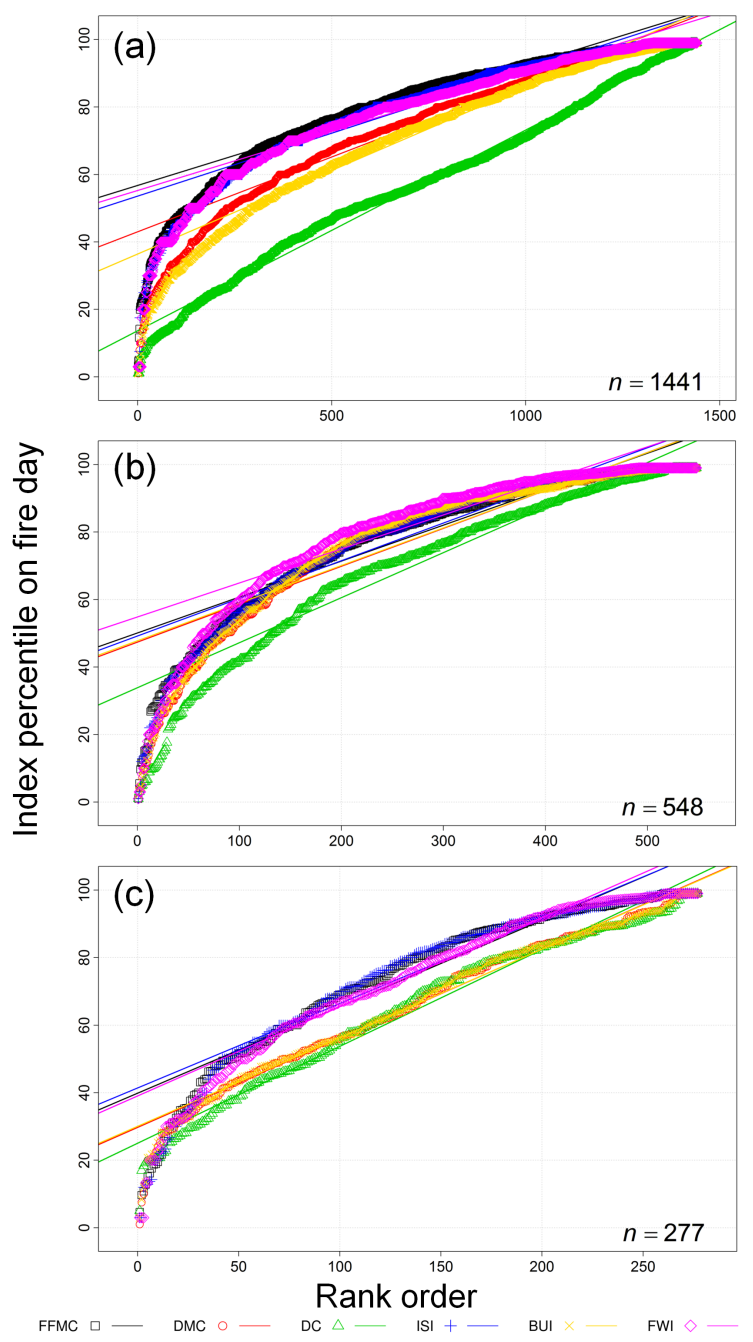

Figure 8. Ranked percentile curves (after Eastaugh et al.'s (2012) approach) of NWP-derived Fire Weather Index components during all wildfire events recorded in the Incident Recording System (IRS) of the Fire and Rescue Service between January 2010 and December 2012 in Great Britain. See Fig. 1 for how to interpret these curves. For each wildfire event, the maximum daily FWI component percentile calculated over the duration of the event was extracted from the NWP grid cell in which the fire occurred. For each season and FWI component, the percentiles of each fire event were plotted in ascending rank order, and regression lines fit using the TheilSen method (Theil, 1950a, b, c; Sen, 1968) - a median-based model that is minimally influenced by outliers (see Sect. 4.3.2). Seasonal plots are shown for (a) spring, (b) summer and (c) autumn. The greater the intercept value and smaller the slope value of a model fit, the more skilful the FWI component is in terms of predicting severe wildfire behaviour. FWI components related to the moisture of quick-drying fine fuels (FFMC and ISI) perform well in all seasons, while FWI components more closely related to the moisture content of slower-drying fuels (DMC and BUI) demonstrate improved performance in summer. The final FWI component performs well in all seasons and is the most skilful FWI System component in summer overall. ther prolonged dry periods or drought (Met Office, 2005), when the fuel moisture of slow-drying dead fuels of larger diameter, and even live fuels, can become lowered. In these cases the slower-reacting FWI components (i.e. DMC, DC and BUI) have a chance to peak, and thus their performance improves slightly in the summer months. Furthermore, despite the decrease in performance of the FFMC/ISI relative to the spring, the improvements seen in the DMC, BUI and DC in the summer ultimately lead to the final component of the system, the FWI, exhibiting the best performance during the summer period.

Figure 8 shows that during all seasons, the DC performs poorly for predicting wildfire occurrence, particularly in spring, when it has almost zero skill. This is likely due to its long time lag of 52 days (time to lose $\sim 2 / 3$ of free moisture above equilibrium; Van Wagner, 1987), which significantly limits its sensitivity to the type of short-term (maximum $\sim 5$ day) weather system changes common in the UK. As an indicator of long-term drought conditions (Camia and Amatulli, 2010), the DC is probably best used to indicate when a particularly severe fire season is imminent, rather than to forecast the timing or location of individual wildfire events. If the DC is elevated while other conditions are favourable for fire establishment (e.g. high wind speeds, high ignition potential of fine fuels), fire intensity and suppression difficulty is likely to be high. Moreover, it may also be the case that under these conditions, vegetation that typically acts as a fuel break can become dry enough to burn, increasing landscape-level fuel connectivity and resulting in larger than normal fires.

\subsubsection{Evaluation of the FWI System components by land cover type}

Seasonal ranked percentile curves and Theil-Sen models for each FWI component at land cover type level, constructed using the maximum value of each FWI component during each wildfire event, are presented in Figs. 9 and 10. These figures highlight that performance of the FWI components varies considerably by vegetation type and season.

During spring (Fig. 9), the best-performing index in grassland and heath/bog/marsh environments is the FFMC, while the FWI outperforms the other indices in coniferous, broadleaved and arable land cover types. FFMC, ISI and FWI perform substantially better than the other components overall in grassland and arable areas, most likely a result of quick-drying fine fuels dominating these land cover types during this season. A similar effect is observed in heath/bog/marsh environments; while deeper slow-drying peat layers may burn during drought conditions, most spring fires occur in the quick-drying canopies of heather stands (Davies and Legg, 2011). In coniferous - and to a lesser extent, broadleaved - environments, performance of the DMC and BUI components is high relative to performance in other land cover types, and in coniferous environments both DMC 

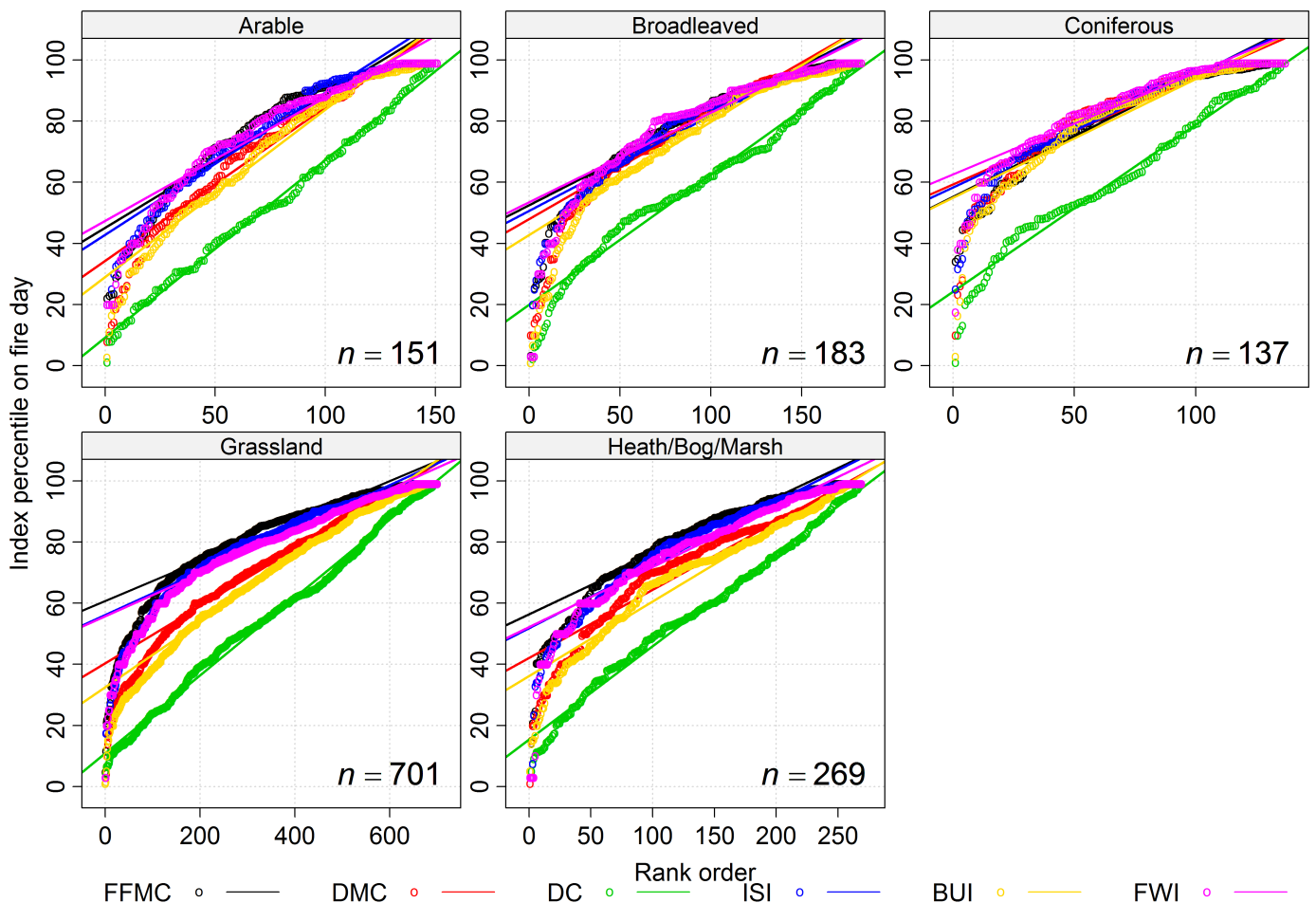

Figure 9. Ranked percentile curves (after Eastaugh et al.'s (2012) approach) of NWP-derived Fire Weather Index components during all spring wildfire events recorded in the Incident Recording System (IRS) of the Fire and Rescue Service between January 2010 and December 2012 in Great Britain, split by dominant land cover type. See Fig. 1 for how to interpret these curves. For each wildfire event, the maximum daily FWI component percentile calculated over the duration of the event was extracted from the NWP grid cell in which the fire occurred. For each season and FWI component, the percentiles of each fire event were plotted in ascending rank order, and regression lines fit using the Theil-Sen method (Theil, 1950a, b, c; Sen, 1968) - a median-based model that is minimally influenced by outliers (see Sect. 4.3.2). The greater the intercept value and smaller the slope value of a model fit, the more skilful a particular FWI component is in terms of predicting severe wildfire behaviour. In spring the FFMC component shows the greatest skill in grassland and heath/bog/marsh land cover types, while the FWI performs best in coniferous and arable environments.

and BUI perform similarly well to the ISI and FFMC. These improvements to DMC and BUI skill likely reflect the increased availability of slow-drying fuels (duff, dead and live woody material) in these forested environments. With the exception of the FFMC, all FWI components perform best in coniferous environments during spring.

During summer (Fig. 10) the FWI component exhibits the greatest predictive skill in grassland, coniferous and heath/bog/marsh land cover types, DMC and BUI are most skilful in broadleaved environments and DC is most skilful in arable environments. The skill of the indices related to slow-drying fuels (DMC, DC, BUI) increases or shows little change relative to the skill in spring for each corresponding land cover type, with the improvements in heath/bog/marsh land cover the most significant. This is consistent with how fire behaviour changes generally from spring to summer in the UK (Sect. 5.5.1). Improvements in these components likely reflect the increasing importance of slower-drying live and dead woody fuels to the overall fuel load in these environments (Arpaci et al., 2013). In heath/bog/marsh areas this may reflect the drying processes that litter, moss and peat layers can undergo in summer, as has been suggested by Davies et al. (2006) and Krivtsov et al. (2008). Conversely, summer FFMC and ISI performance decreases relative to spring in grassland, broadleaved and arable environments. In summer, the skill of the FWI component increases in heath/bog/marsh, coniferous and broadleaf environments, decreases in arable environments and shows no change in grassland environments. With the exception of the DC, in coniferous environments during summer the performance of all FWI components is very high, both relative to other environments during summer and in comparison to coniferous environments during spring. Increases in the skill of all components relative to spring are also observed in heath/bog/marsh environments.

The overall poor DC performance found across all seasons in Sect. 5.5.1 is also observed when indices are evaluated by vegetation type. While DC performs well relative to other components in arable environments in summer, all other components generally perform poorly in both seasons. These observations are challenging to interpret but may be a 

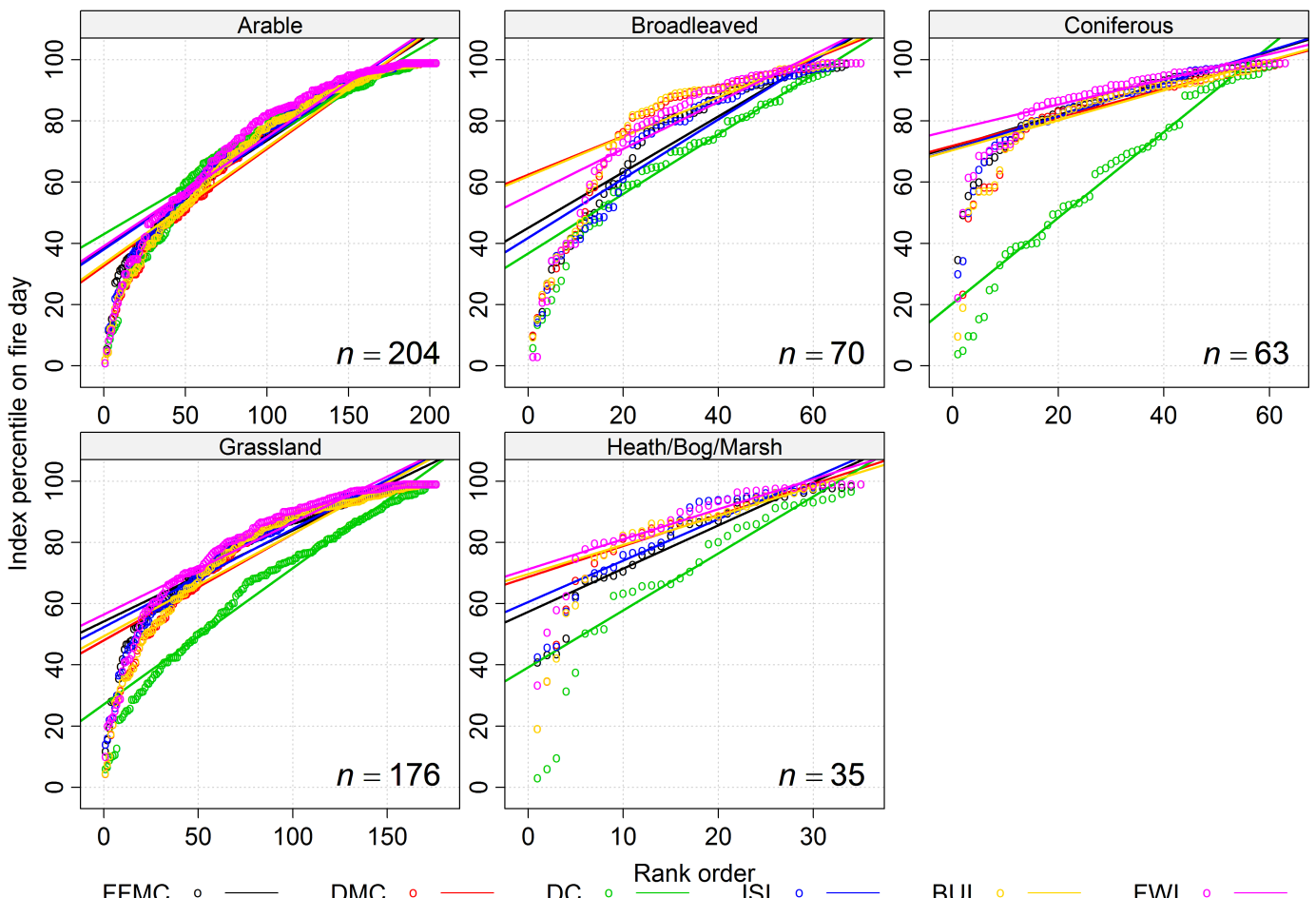

Figure 10. Ranked percentile curves (after Eastaugh et al.'s (2012) approach) of NWP forecast-derived Fire Weather Index components during all summer wildfire events recorded in the Incident Recording System (IRS) of the Fire and Rescue Service between January 2010 and December 2012 in Great Britain, split by dominant land cover type. See Fig. 1 for how to interpret these curves. For each wildfire event, the maximum daily FWI component percentile calculated over the duration of the event was extracted from the NWP grid cell in which the fire occurred. For each season and FWI component, the percentiles of each fire event were plotted in ascending rank order, and regression lines fit using the Theil-Sen method (Theil, 1950a, b, c; Sen, 1968) - a median-based model that is minimally influenced by outliers (see Sect. 4.3.2). The greater the intercept value and smaller the slope value of a model fit, the more skilful the FWI component is in terms of predicting severe wildfire behaviour. In the summer months the FWI component has the greatest skill grassland, heath/bog/marsh and coniferous environments, the DC has the greatest skill in arable environments and the DMC/BUI have the greatest skill in broadleaved environments.

result of farming practices and societal factors (e.g. ignitions in baled crops) masking the impacts of meteorology on fire activity in these environments.

\subsubsection{Raw FWI component values during historic wildfires: the FFMC as an on/off switch for fire danger?}

While advocating the adoption of our percentile-based approach to fire danger forecasting in the UK, we also examined the "raw" component (i.e. non-percentile) values of the NWP-derived FWI component forecasts in grid cells where wildfire events occurred. As has been shown in other studies (e.g. de Groot et al., 2005, 2007; Davies and Legg, 2008; Wotton, 2009), non-spatially sensitive thresholding behaviour was observed in FFMC. Distributions of the maximum FFMC values during wildfire events in 2010-2012 are shown in Fig. 11, where $90 \%$ of all fires are seen to have occurred above an FFMC value of 72 in spring, 74 in summer and 69 in autumn. Below these values, ignitions appear to be rarely sustained. This suggests that there may be some merit to restricting the forecast fire danger level based upon the raw FFMC value, regardless of the forecast value of any other FWI component percentile. No similar behaviour is observed in any of the other indices, however, justifying the use of a percentile-based approach to give more detailed information on fire danger once the FFMC surpasses these "sustained ignition" thresholds.

\section{Limitations and conclusions}

During suitable weather conditions, multiple landscape-scale fires can burn simultaneously across large parts of the UK. A UK FDRS can be used to forecast such problematic periods, so as to better forewarn FRS and government agencies (Eastaugh et al., 2012). The current UK FDRS - the MOFSI (Met Office, 2015) - is based upon the FWI component of the Canadian Forest FWI System, as calculated from daily NWP forecasts made up to 5 days ahead. We have investigated improvements to the current MOFSI, examining all 


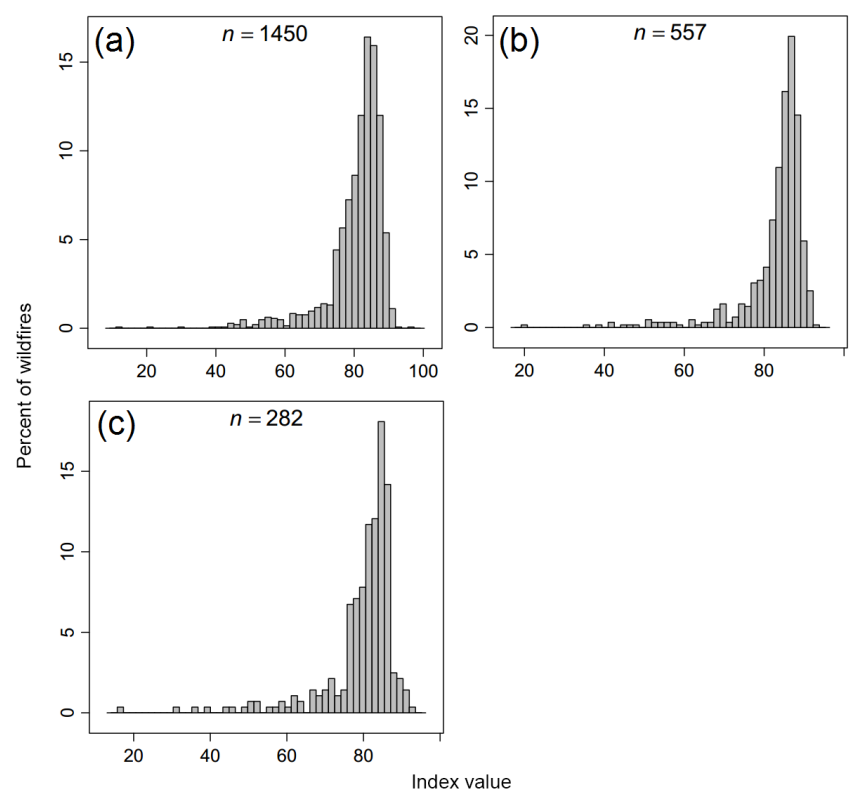

Figure 11. Distribution of raw FFMC values on wildfire days in (a) spring, (b) summer and (c) autumn in Great Britain, as recorded in the Fire and Rescue Service Incident Recording System database between January 2010 and December 2012. Thresholding behaviour is apparent in all seasons. Of all fires, $90 \%$ during this period occurred above a FFMC value of 72 in spring, 74 in summer and 69 in autumn. We suggest that a revised fire danger rating system for the UK may be able to make use of these threshold values in addition to FWI component percentile information for assessing fire danger.

components of the FWI System, as suggested by Van Wagner (1988), and using a new method to identify "extremes" based on seasonally and spatially varying percentiles. This approach appears well justified, as we found an extreme spatial bias in the current MOFSI by which UK fire danger is classified using spatially fixed thresholds (Sect. 5.3).

FWI data were investigated during periods of historic wildfire activity, using data from the Great Britain FRS IRS for 2010-2012. We found that the 75th, 90th and 99th percentiles of at least one FWI component were exceeded during 85,61 and $18 \%$ of all wildfires incidents between 2010 and 2012 respectively. We also compared a "forecast" from our percentile-based FDRS to a "forecast" issued by the existing MOFSI for a period of exceptional nationwide wildfire activity (2 May 2011; Kitchen, 2012), using contingency tables and the EDI. We found that the percentile-based approach $(E D I=0.22)$ highlights extreme fire danger with far more skill than the MOFSI $(E D I=0.08)$. Furthermore, a seasonal intercomparison of the FWI components was carried out using the Eastaugh et al. (2012) percentile ranking approach, nationally and by land cover type. The FFMC, FWI and ISI components stand out as the best predictors of wildfire activity in spring (the peak wildfire season) both nationally and in grassland and heath/bog/marsh land cover types, the environments in which most fire activity occurs. This is broadly in agreement with the findings of Legg et al. (2007) for Scotland. During summer, the FWI component was generally the best performing (see Sect. 5.5.2 for further details). It was noted that during both spring and summer, FWI components generally exhibited the greatest skill in coniferous environments - possibly due to the initial development of the FWI System in Canadian forests - but were relatively poor in arable ones, possibly due to human activity more strongly driving fuel availability and fire occurrence in these areas. We also note that "raw" FFMC data may have a useful role to play in any future UK FDRS, since most landscape fires appear to occur within a relatively narrow FFMC range (see Sect. 5.5.3).

There are several caveats associated with this study.

- The NWP FWI data set used to create the percentilebased FDRS developed herein spans a relatively short time period (2010-2013) and, accordingly, so does the fire activity data used to evaluate it. While a comparison with a 30-year met station-derived FWI data set (Sect. 5.2) indicates that the NWP data form a broadly representative UK "FWI climatology", it may not fully capture the most extreme fire danger conditions experienced over a multi-decadal period. This work therefore could be enhanced by making use of e.g. a long-term climate reanalysis data set blended with actual rainfall observations (Field et al., 2015) as the basis for the FWI climatology. Furthermore, a longer-term fire activity data set (that also includes data from Northern Ireland) may give a more representative picture of fire occurrence in the UK. While these data are currently unavailable, the continued operation of the IRS will greatly enhance our understanding of UK fire activity in the near future.

- Developing landscape fires require an ignition source in addition to appropriate meteorological and fuel conditions conducive to fire spread, and in the UK such ignitions overwhelmingly come from human activity (Davies et al., 2006). To some extent, relationships we find between fire occurrence and elevated FWI components might therefore also be strongly influenced by human behaviour, such as more outdoor recreational activity during periods of warm weather and/or more spring management fires being conducted. Nevertheless, if the right meteorological conditions are not also present, any ignition will be unlikely to lead to a sustained wildfire.

- While a percentile-based FDRS may highlight local fire danger better than an uncalibrated adoption of the FWI System, percentiles are unlikely to relate well to fire behaviour characteristics in fuels, and so are likely to be of limited use in fire suppression activities. To exploit the full potential of the FWI System, new empirical relationships need to be established between the FWI com- 
ponents and fuel moisture/fire behaviour in UK fuels. Currently, however, these relationships are poorly understood.

Despite these limitations, our study provides new insights into the applicability of the Canadian FWI System to the UK and also very likely to similar northern European environments. Whilst there are clearly limits as to what can ultimately be achieved by applying this sort of statistical driven approach to the empirically developed FWI System, we believe that our approach offers a significant advance on the current MOFSI methodology and considerable potential benefits for UK FRS and government agencies.

\section{Data availability}

NWP and meteorological station data used in this work were made available to us upon request by the UK Met Office (2013a, b) (http://www.metoffice.gov.uk/). The IRS database was made available to us upon request by the Department for Communities and Local Government (https://www.gov.uk/government/organisations/ department-for-communities-and-local-government).

The UK Land Cover Map (LCM) 2007 is available from CEH (http://www.ceh.ac.uk/services/ land-cover-map-2007). The National Forest Inventory (NFI) is available from the Forestry Commission (http://www.forestry.gov.uk/datadownload). The Ordnance Survey MasterMap ${ }^{\circledR}$ Topography Layer is available from the Ordnance Survey (https://www.ordnancesurvey.co.uk/ business-and-government/products/topography-layer.html).

Acknowledgements. This work was supported by the Natural Environment Research Council (NERC) through a PURE Associateship (grant number PA13-017) and a PhD studentship (Mark C. De Jong). Martin J. Wooster is supported by the NERC National Centre for Earth Observation (NCEO). We are very grateful for advice given by members of the UK Chief Fire Officer's Association (CFOA) and England and Wales Wildfire Forum (EWWF), and we also thank the Department for Communities and Local Government (DCLG), Forestry Commission England (FCE), Ordnance Survey (OS) and the Centre for Ecology and Hydrology (CEH) for use of the various data sets described herein.

We would also like to thank the four reviewers of earlier versions of this manuscript for their helpful comments and suggestions.

Edited by: R. Lasaponara

Reviewed by: P. Fernandes and three anonymous referees

\section{References}

Albertson, K., Aylen, J., Cavan, G., and McMorrow, J.: Forecasting the outbreak of moorland wild fires in the English Peak District, J. Environ. Manage., 90, 2642-2651, 2009.
Alexander, M. E. and Cruz, M. G.: Assessing the effect of foliar moisture on the spread rate of crown fires, Int. J. Wildland Fire, 22, 415-427, 2012.

Alexander, M. E. and de Groot, W. J.: Fire behaviour in Jack pine stands as related to the Canadian Forest Fire Weather Index (FWI) System. Canadian Forestry Service, Northern Forestry Centre, Edmonton, Alberta, 1988.

Anderson, S. A. J. and Anderson, W. R.: Predicting the elevated dead fine fuel moisture content in gorse (Ulex europaeus L.) shrub fuels, Can. J. Forest Res., 39, 2355-2368, 2009.

Anderson, W. R., Cruz, M. G., Fernandes, P. M., McCaw, L., Vega, J. A., Bradstock, R. A., Fogarty, L., Gould, J., McCarthy, G., Marsden-Smedley, J. B., Matthews, S. M., Mattingley, G., Pearce, H. G., and van Wilgen, B. W.: A generic, empirical-based model for predicting rate of fire spread in shrublands, Int. J. Wildland Fire, 24, 443-460, 2015.

Andrews, P. L., Loftsgaarden, D. O., and Bradshaw, L. S.: Evaluation of fire danger rating indexes using logistic regression and percentile analysis, Int. J. Wildland Fire, 12, 213-226, 2003.

Arpaci, A., Eastaugh, C. S., and Vacik, H.: Selecting the best performing fire weather indices for Austrian ecoregions, Theor. Appl. Climatol., 114, 393-406, 2013.

Bedia, J., Herrera, S., and Gutiérrez, J. M.: Assessing the predictability of fire occurrence and area burned across phytoclimatic regions in Spain, Nat. Hazards Earth Syst. Sci., 14, 53-66, doi:10.5194/nhess-14-53-2014, 2014.

Camia, A. and Amatulli, G.: Weather Factors and Fire Danger in the Mediterranean, in: Earth Observation of Wildland Fires in Mediterranean Ecosystems, edited by: Chuveico, E., SpringerVerlag, Berlin Heidelberg, 71-82, 2009.

Camia, A. and Amatulli, G.: Climatology of FWI over Europe: fire danger anomalies and index percentile rankings, in: Proceedings of the VI International Conference on Forest Fire Research, 1518 November 2010, ADAI/CEIF, Coimbra, Portugal, edited by: Viegas, D. X., 2010.

Centre for Ecology \& Hydrology (CEH): Land Cover Map 2007 (LCM2007), available at: http://www.ceh.ac.uk/services/ land-cover-map-2007, last access: May 2016.

Chuvieco, E., Gonzalez, I., Verdu, F., Aguado, I., and Yebra, M.: Prediction of fire occurrence from live fuel moisture content measurements in a Mediterranean ecosystem, Int. J. Wildland Fire, 18, 430-441, 2009.

Countryside and Rights of Way Act: c. 37, The Stationery Office, London, 2000.

Davies, G. M. and Legg, C. J.: Developing a live fuel moisture model for moorland fire danger rating, in: Modelling, Monitoring and Management of Forest Fires, edited by: de la Heras, J., Brebbia, C. A., Viegas, D. X., and Leone, V., WIT Trans. Ecol. Envir., 119, 225-236, 2008.

Davies, G. M. and Legg, C. J.: Fuel moisture thresholds in the flammability of Calluna vulgaris, Fire Technol., 47, 421-436, 2011.

Davies, G. M, Legg, C. J., Smith, A., and MacDonald, A.: Developing shrub fire behaviour models in an oceanic climate: Burning in the British Uplands, Forest Ecol. Manag., 234, Supplement 1, S107, 2006.

Davies, G. M., Gray, A., Hamilton, A., and Legg, C. J.: The future of fire management in the British uplands, International Journal of Biodiversity Science \& Management, 4, 127-147, 2008. 
Davies, G. M., Legg, C. J., Smith, A., and MacDonald, A.: Rate of spread of fires in Calluna vulgaris-dominated moorlands, J. Appl. Ecol., 46, 1054-1063, 2009.

de Groot, W. J., Wardati, and Wang, Y.: Calibrating the Fine Fuel Moisture Code for grass ignition potential in Sumatra, Indonesia, Int. J. Wildland Fire, 14, 161-168, 2005.

de Groot, W. J., Field, R. D., Brady, M. A., Roswintiarti, O., and Mohamad, M.: Development of the Indonesian and Malaysian Fire Danger Rating Systems. Mitigation and Adaptation Strategies for Global Change, 12, 165-180, 2007.

DCLG (Department for Communities and Local Government): Incident Recording System for Fire and Rescue Services, London, UK, available at: https://www.gov.uk/government/publications/ incident-recording-system-for-fire-and-rescue-authorities, last access 5 November 2015, 2012.

DCLG (Department for Communities and Local Government): Incident Recording System (IRS) data for fire and rescue authorities, Data set, London, UK, 2013.

Doswell, C. A., Davies-Jones, R., and Keller, D. L.: On summary measures of skill in rare event forecasting based on contingency tables, Weather Forecast., 5, 576-585, 1990.

Dowdy, A. J., Mills, G. A., Finkele, K., and de Groot, W.J.: Australian fire weather as represented by the McArthur Forest Fire Danger Index and the Canadian Forest Fire Weather Index, CAWCR Technical Report No. 10, Bureau of Meteorology and CSIRO, Melbourne, Australia, 2009.

Dowdy, A. J., Mills, G. A., Finkele, K., and de Groot, W. J.: Index sensitivity analysis applied to the Canadian Forest Fire Weather Index and the McArthur Forest Fire Danger Index, Meteorol. Appl., 17, 298-312, 2010.

Eastaugh, C. S. and Hasenauer, H.: Deriving forest fire ignition risk with biogeochemical process modelling, Environ. Modell. Softw., 55, 132-142, 2014.

Eastaugh, C. S., Arpaci, A., and Vacik, H.: A cautionary note regarding comparisons of fire danger indices, Nat. Hazards Earth Syst. Sci., 12, 927-934, doi:10.5194/nhess-12-927-2012, 2012.

Ferro, C. A. T. and Stephenson, D. B.: Extremal dependence indices: improved verification measures for deterministic forecasts of rare binary events, Weather Forecast., 26, 699-713, 2011.

Field, R. D., Spessa, A. C., Aziz, N. A., Camia, A., Cantin, A., Carr, R., de Groot, W. J., Dowdy, A. J., Flannigan, M. D., Manomaiphiboon, K., Pappenberger, F., Tanpipat, V., and Wang, X.: Development of a Global Fire Weather Database, Nat. Hazards Earth Syst. Sci., 15, 1407-1423, doi:10.5194/nhess-151407-2015, 2015.

Finkele, K., Mills, G. A., Beard, G., and Jones, D. A.: National daily gridded soil moisture deficit and drought factors for use in prediction of forest fire danger index in Australia, Research Report No. 119, Bureau of Meteorology Research Centre, Australia, 2006.

Fogarty, L. G., Pearce, H. G., Catchpole, W. R., and Alexander, M. E.: Adoption vs. adaptation: lessons from applying the Canadian Forest Fire Danger Rating System in New Zealand, in: Proceedings of the III International Conference on Forest Fire Research, 16-20 November 1998, Luso, Portugal, edited by: Viegas, D. X., University of Coimbra, Coimbra, 1011-1028, 1998.

Forestry Commission England: National Forest Inventory data, Data set, available at: http://www.forestry.gov.uk/datadownload, last access: May 2016, 2012.
Granato, G. E.: Kendall-Theil Robust Line (KTRLine - version 1.0) - A visual basic program for calculating and graphing robust nonparametric estimates of linear-regression coefficients between two continuous variables, U.S. Geological Survey Techniques and Methods, chap. A7, book 4, 2006.

Helsel, D. R. and Hirsch, R. M.: Statistical methods in water resources - Hydrologic analysis and interpretation. U.S. Geological Survey Techniques of Water-Resources Investigations, chap. A3, book 4, 2002.

Hoadley, J. L., Westrick, K., Ferguson, S. A., Goodrick, S. L., Bradshaw, L., and Werth, P.: The effect of model resolution in predicting meteorological parameters used in fire danger rating, J. Appl. Meteorol., 43, 1333-1347, 2004.

Karali, A., Hatzaki, M., Giannakopoulos, C., Roussos, A., Xanthopoulos, G., and Tenentes, V.: Sensitivity and evaluation of current fire risk and future projections due to climate change: the case study of Greece, Nat. Hazards Earth Syst. Sci., 14, 143-153, doi:10.5194/nhess-14-143-2014, 2014.

Kitchen, K.: Fire Weather conditions during Spring 2011, Report for the Natural England and the Countryside Council for Wales, Met Office, Exeter, UK, available at: http://www.metoffice. gov.uk/public/weather/fire-severity-index/documents/Spring 2011_fire_weather_conditions_tcm6-35277.pdf, last access 5 November 2015, 2012.

Kitchen, K., Marno, P., Legg, C., Bruce, M., and Davies, M.: Developing a fire danger rating system for the United Kingdom, Forest Ecol. Manag., 234, Supplement 1, S21, 2006.

Krivtsov, V., Gray, A., Valor, T., Legg, C. J., and Davies, G. M.: The fuel moisture content of peat in relation to meteorological factors, WIT Trans. Ecol. Envir., 119, 193-200, 2008.

Lawson, B. D. and Armitage, O. B.: Weather guide for the Canadian Forest Fire Danger Rating System, Natural Resources Canada, Canadian Forest Service, Edmonton, AB, 2008.

Lee, B. S., Alexander, M. E., Hawkes, B. C., Lynham, T. J., Stocks, B. J., and Englefield, P.: Information systems in support of wildland fire management decision making in Canada, Comput. Electron. Agr., 37, 185-198, 2002.

Legg, C. J. and Davies, G. M.: FireBeaters phase II report, Report to Scottish Natural Heritage, University of Edinburgh, Edinburgh, 2009.

Legg, C. J., Davies, G. M., Marno, P., and Kitchen, K.: Developing a Fire Danger Rating System for the UK: FireBeaters Phase I final report, Report to the Scottish Wildfire Forum, The University of Edinburgh, Edinburgh and the Met Office, Exeter, 2007.

MacKinnon, F.: How GIS and fire indices can be used in developing a fire prediction model for Scotland. Master's dissertation, University of Edinburgh, available at: http://hdl.handle.net/1842/ 2456, last access: 5 November 2015, 2008.

McMorrow, J., Walker, J., and Karunasaagarar, A.: What the databases say: opportunities and limitations for spatial analysis of wildfire in Great Britain, Poster presentation at: 5th International Conference on Wildland Fire, 9-13 May 2011, Sun City, South Africa, 2011.

Met Office: The Met Office Fire Severity Index for England and Wales, Prepared for: Countryside Agency, Countryside Council for Wales and the Forestry Commission, MetOffice ref: M/BO/P87, Met Office, Exeter, UK, 2005.

Met Office: Numerical weather prediction data, Data set, Met Office, Exeter, UK, 2013a. 
Met Office: Meteorological observation station data, Data set, Met Office, Exeter, UK, 2013b.

Met Office: England and Wales Fire Severity Index, available at: http://www.metoffice.gov.uk/public/weather/fire-severity-index (last access: 5 November 2015), 2015.

Milne, R. and Brown, T. A.; Carbon in the Vegetation and Soils of Great Britain, J. Environ. Manage., 49, 413-433, 1997.

Morton, D., Rowland, C., Wood, C. Meek, L., Marston, C., Smith, G., Wadsworth, R., and Simpson, I. C.: Final Report for LCM2007 - the new UK land cover map, NERC/Centre for Ecology and Hydrology, UK, Countryside Survey Technical Report No 11/07, 112 pp. (CEH Project Number: C03259), 2011.

Ordnance Survey: MasterMap ${ }^{\circledR}$ Topography Layer [Data set], Ordnance Survey, Southampton, ${ }^{\circledR}$ Crown copyright, available at: https://www.ordnancesurvey.co.uk/business-and-government/ products/topography-layer.html, last access: May 2016, 2014.

Padilla, M. and Vega-García, C.: On the comparative importance of fire danger rating indices and their integration with spatial and temporal variables for predicting daily human-caused fire occurrences in Spain, Int. J. Wildland Fire, 20, 46-58, 2011.

Palheiro, P. M., Fernandes, P., and Cruz, M. G. A fire behaviourbased fire danger classification for maritime pine stands: Comparison of two approaches, Forest Ecol. Manag., 234, Supplement 1, S54, 2006

Scottish Government: Fire and Rescue Service Wildfire Operational Guidance, available at: http://www.gov.scot/Publications/2013/ 10/6118, last access: 5 November 2015, 2013.

Sen, P. K.: Estimates of regression coefficient based on Kendall's tau, J. Am. Stat. Assoc., 63, 1379-1389, 1968.

Stocks, B. J., Lawson, B. D., Alexander, M. E., Van Wagner, C. E., McAlpine, R. S., Lynham, T. J., and Dube, D. E.: The Canadian Forest Fire Danger Rating System: an overview, Forest. Chron., 65, 450-457, 1989.

Taylor, S. W. and Alexander, M. E.: Science, technology and human factors in fire danger rating: the Canadian experience, Int. J. Wildland Fire, 15, 121-135, 2006.
Theil, H.: A rank invariant method for linear and polynomial regression analysis, Nederlandse Akademie van Wetenschappen Proceedings Series A, 53, 386-392, 1950a.

Theil, H.: A rank invariant method for linear and polynomial regression analysis, Nederlandse Akademie van Wetenschappen Proceedings Series A, 53, 521-525, 1950 b.

Theil, H.: A rank invariant method for linear and polynomial regression analysis, Nederlandse Akademie van Wetenschappen Proceedings Series A, 53, 1397-1412, 1950c.

Van Wagner, C. E.: Development and Structure of the Canadian Forest Fire Weather Index System, Technical Report 35, Canadian Forestry Service, Ottawa, ON, 1987.

Van Wagner, C. E.: Note on the use of the Canadian Forest Fire Weather Index System in Other Countries. Canadian Forestry Service, Petawawa National Forestry Institute, Chalk River, ON, 1988.

Venäläinen, A., Korhonen, N., Hyvärinen, O., Koutsias, N., Xystrakis, F., Urbieta, I. R., and Moreno, J. M.: Temporal variations and change in forest fire danger in Europe for 1960-2012, Nat. Hazards Earth Syst. Sci., 14, 1477-1490, doi:10.5194/nhess-141477-2014, 2014.

Verbesselt, J., Somers, B., van Aardt, J., Jonckheere, I., and Coppin, P.: Monitoring herbaceous biomass and water content with SPOT VEGETATION time-series to improve fire risk assessment in savanna ecosystems, Remote Sens. Environ., 101, 399-414, 2006a

Verbesselt, J., Jonsson, P., Lhermitte, S., van Aardt, J., and Coppin, P.: Evaluating satellite and climate data-driven indices as fire risk indicators in savanna ecosystems, IEEE T. Geosci. Remote, 44, 1622-1632, $2006 \mathrm{~b}$.

Viegas, D. X., Bovio, G., Ferreira, A., Nosenzo, A., and Sol, B.: Comparative study of various methods of fire danger evaluation in southern Europe, Int. J. Wildland Fire, 9, 235-246, 1999.

Viegas, D. X., Piñol, J., Viegas, M. T., and Ogaya, R.: Estimating live fine fuels moisture content using meteorologically-based indices, Int. J. Wildland Fire, 10, 223-240, 2001.

Wotton, B. M.: Interpreting and using the outputs of the Canadian Forest Fire Danger Rating System in research applications, Environ. Ecol. Stat., 16, 107-131, 2009. 